\title{
The influence of iron level on corrosion of high-pressure die-cast LM24 alloy
}

DOI:

$10.1051 / \mathrm{metal} / 2016036$

\section{Document Version}

Accepted author manuscript

Link to publication record in Manchester Research Explorer

\section{Citation for published version (APA):}

Rahimi, E., Thompson, G., Scamans, G., \& Fan, Z. (2016). The influence of iron level on corrosion of highpressure die-cast LM24 alloy. Metallurgical Research and Technology, 113(6), [604]. https://doi.org/10.1051/metal/2016036

\section{Published in:}

Metallurgical Research and Technology

\section{Citing this paper}

Please note that where the full-text provided on Manchester Research Explorer is the Author Accepted Manuscript or Proof version this may differ from the final Published version. If citing, it is advised that you check and use the publisher's definitive version.

\section{General rights}

Copyright and moral rights for the publications made accessible in the Research Explorer are retained by the authors and/or other copyright owners and it is a condition of accessing publications that users recognise and abide by the legal requirements associated with these rights.

\section{Takedown policy}

If you believe that this document breaches copyright please refer to the University of Manchester's Takedown Procedures [http://man.ac.uk/04Y6Bo] or contact uml.scholarlycommunications@manchester.ac.uk providing relevant details, so we can investigate your claim.

\section{OPEN ACCESS}


The influence of iron level on corrosion of high-pressure die-cast LM24 alloy

Ehsan Rahimi a , Email: ehsan.rahimi.dme@gmail.com

George E. Thompson a, Email: george.thompson@manchester.ac.uk,

Geoff M. Scamans b, Email: geoff.scamans@brunel.ac.uk

Z. Fan b, Email: mtstzzf@brunel.ac.uk

a Corrosion and Protection Centre, UMIST, P.O. Box 88, Manchester, M60 1QD, UK

b BCAST (Brunel Centre for Advanced Solidification Technology), Brunel University, Middlesex West London, Uxbridge, Middlesex UB8 3PH, UK

\begin{abstract}
:
Iron is a detrimental alloying element for aluminium alloys; however, it is essential for facilitating die ejection in high-pressure die-casting process. Hence, studying the effect of iron on the corrosion performance of HPDC aluminium alloys is useful to find an optimal iron content for a specific alloy. Four LM24 alloys with 0.6 wt.\%Fe, 0.8 wt.\%Fe, 1.2 wt.\%Fe and 2 wt.\%Fe additions have been examined in this study. In addition to the differences in iron levels, the copper and manganese contents varied in two alloys. The corrosion performance of the alloy specimens was evaluated by electrochemical noise and electrochemical polarisation measurements, and scanning Kelvin probe force microscopy. The microstructures of the individual alloy specimens were observed by scanning electron microscopy prior to and after each corrosion evaluation experiment. The results show that more corrosion products accumulated in the alloys with higher iron additions, and this led to reduction of cathodic reaction rates in the aqueous aggressive chloride solution. An increased $\mathrm{Mn} / \mathrm{Fe}$ ratio causes the distribution of iron-rich phase particles and cathodic sites across the surface of the alloy. Hence, the compositional potential gradient of the phases throughout the surface decreases. In addition, the potential gradient of the phases also depends on the surface roughness of the phase particles; therefore, the alloys with the larger iron-rich phase particles show the highest potential gradients.
\end{abstract}

Keywords: ALUMINIUM; IRON; INTERMETALLICS; AFM;CORROSION 


\section{Introduction:}

Iron is one of the most detrimental impurities for mechanical properties of aluminium alloys owing to its low solubility (less than 0.04 wt. \%) which causes the formation of various, harmful iron-rich intermetallic compounds [1-3]. Under equilibrium conditions, the dominant Fe-bearing phase particles are $\mathrm{Al}_{3} \mathrm{Fe}$ and, under non-equilibrium conditions, the excess iron leads to nucleation of iron-rich phases containing silicon or it may be present in the supersaturated solid solution [3]. The Al-Fe-Si ternary phase particles have been identified in several reports in the forms of $\beta$-AlFeSi $\left(\mathrm{Al}_{5} \mathrm{FeSi}\right)$ platelets with monoclinic structures that are detrimental to alloy strength and ductility due to their morphology [4]. Generally, the dominant phase particles are $\alpha$-AlFeSi $\left(\mathrm{Al}_{8} \mathrm{Fe}_{2} \mathrm{Si}\right)$ phase particles that have a star-shaped, blocky form or polyhedral morphology with hexagonal or cubic structures depending on the presence of manganese, which leads to ironneutralisation and the formation of small or large iron-rich phase particles [3, 511]. The main iron sources in aluminium alloys are steel tools for processing of primary aluminium and scrap materials in the recycling process [12]. There is a critical iron level above which the formation of the $\beta$-platelets is promoted. This level depends on the cooling rate, eutectic modification, manganese content and silicon content [12]. Previous researches have shown that iron-rich phases are nobler than the aluminium matrix and they can be the active sites for cathodic reactions such as oxygen reduction or hydrogen evolution reactions. Hence, the $\mathrm{pH}$ increases locally. Indeed, the iron-rich phases remain inert and the dissolution takes place in their immediate vicinity due to the local alkalization generated [1320]. It is well known that oxygen reduction controls the localized corrosion of aluminium; however, over a long period of corrosion, the oxygen reduction, which occurs on the iron-rich phase particles in the aluminium matrix, may be suppressed due to the formation of bulky or nodular corrosion products [21]. One of the characteristics of the corrosion product is its adhesive properties, which depends on $\mathrm{NaCl}$ concentration [22, 23]. Seri et al. [24] have shown that the adhesive ability of corrosion products becomes weaker in more concentrated $\mathrm{NaCl}$ environments. They also claimed that the preferential dissolution of iron in the intermetallic compounds and subsequent deposition of ferrous ions occurs in a dilute $\mathrm{NaCl}$ environment and, in the concentrated solution, the iron-rich intermetallic phase particles provide the cathodic sites at which the oxygen 
reduction takes place. If the excess iron is present in solid solution, the dissolution kinetics increase due to the nobility of iron rather than aluminium [1]. A previous study on LM24 alloy containing iron-rich phase particles has shown that these intermetallic phase particles are nobler than the aluminium matrix in the potential maps generated by scanning Kelvin probe force microscopy. The potential difference between the iron-rich phases and the matrix depends on the forming process of the alloy [25]. Consequently, reducing the Fe levels in $\mathrm{Al}$ alloys or modifying the crystal structure of the iron-rich intermetallics in order to improve mechanical properties is desirable. This could be more important in the recycling process due to the presence of scrap materials that contain more iron. However, iron is not always detrimental to aluminium alloys. For instance, iron has been used in high-pressure die-casting (HPDC) of aluminium alloys to improve die release that is a costly process. Hence, obtaining the appropriate level of iron in which the detrimental intermetallic compounds are eliminated, and the iron content is sufficiently high for die soldering in the high-pressure die-casting process is essential. Apart from controlling the iron level to prevent the formation of detrimental iron-rich intermetallics, introducing some elements to the alloy composition leads to modification of the structure of the intermetallic compounds to high symmetry structures. For instance, addition of manganese increases the nucleation tendency of $\mathrm{Al}_{15}(\mathrm{Fe}, \mathrm{Mn})_{3} \mathrm{Si}_{2}$ (or $\alpha-\mathrm{AlFeMnSi}$ ) instead of $\alpha-\mathrm{Al}_{8} \mathrm{Fe}_{2} \mathrm{Si}$ and $\beta-\mathrm{Al}_{5} \mathrm{FeSi}$; further, the former phases have more compact morphologies. CALPHAD simulations performed by Fang et al. [26] on LM24 and LM25 alloys have shown the influence of $\mathrm{Si}, \mathrm{Mn}$ and $\mathrm{Cu}$ on various $\mathrm{Fe}$ contents in a diagram reported in Figure 1. The experimental data of HPDC samples have also been compared with the results of the simulations in their research. Although some researchers worked on the detrimental effects of the iron impurities on the corrosion performance of aluminium alloys, no research has been reported on alloys containing a high copper content.

The influence of iron level on the corrosion of low copper containing aluminium alloys (Al-Si alloys) has been previously reported in the literature. In this work, the variation of the corrosion performance of a high copper aluminium alloy (LM24) with iron additions has been investigated. The practical interest in such studies is related to the design of the alloys for high-pressure die-casting in which the 
presence of iron is necessary for facilitating die ejection. In this context, the effect of manganese and copper additions on the iron-rich phases and the corrosion performance are reported.

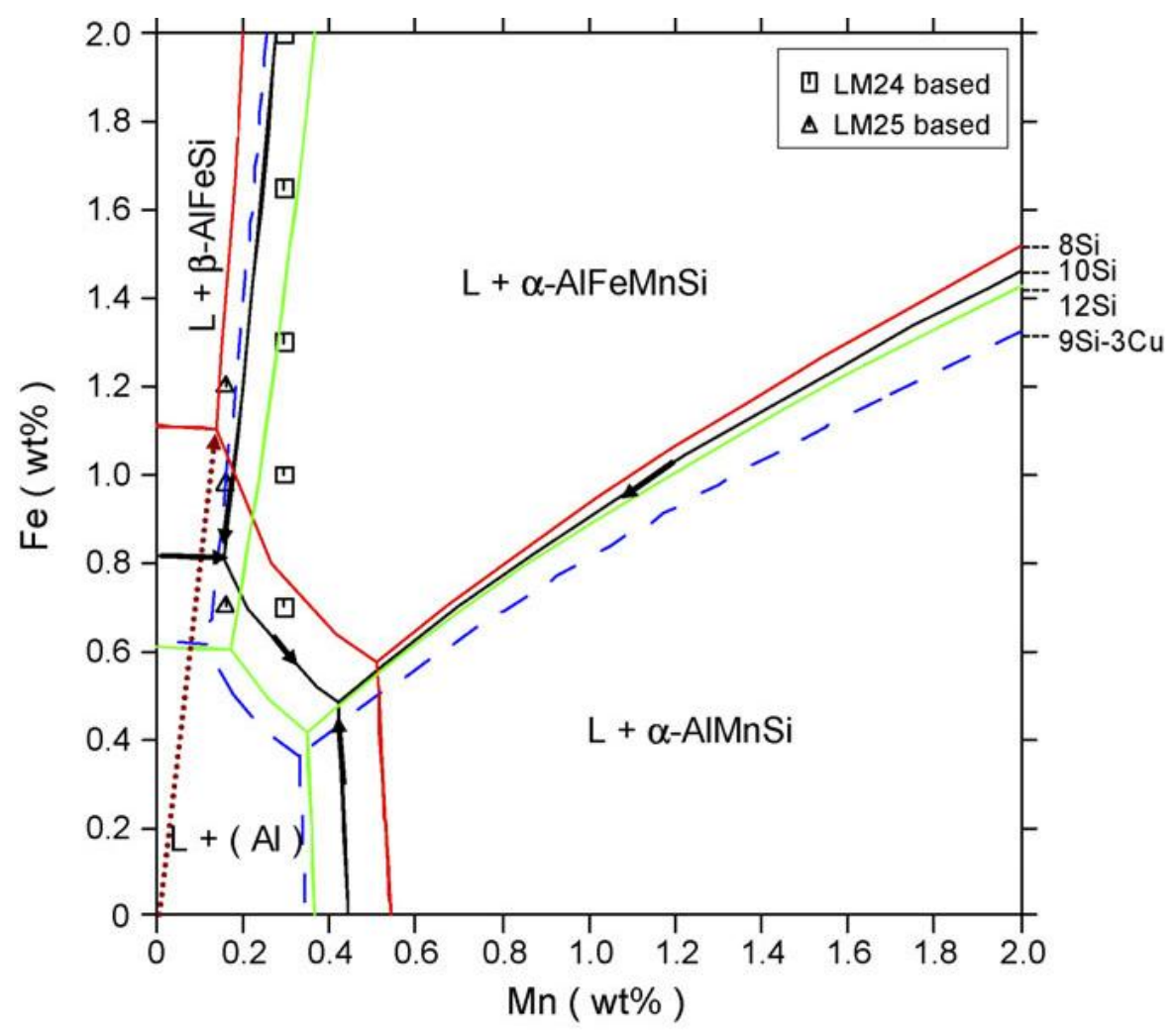

Figure 1. The effect of $\mathrm{Si}, \mathrm{Mn}$ and $\mathrm{Cu}$ on various Fe contents in aluminium alloys [26]. Experimental:

In order to investigate the effect of iron content on the corrosion of LM24 alloy, four specimens with 0.6 wt.\%Fe, 0.8 wt.\%Fe, 1.2 wt.\%Fe and 2 wt.\%Fe additions were made by high-pressure die-casting at BCAST, Brunel University. The samples were melted at $730^{\circ} \mathrm{C}$, degassed with $\mathrm{N}_{2}$ for 3 minutes and kept at $730^{\circ} \mathrm{C}$ for 30 minutes prior to casting. The pouring temperature was between $650^{\circ} \mathrm{C}$ and $660^{\circ} \mathrm{C}$. The temperature of the shot sleeve out surface was $150^{\circ} \mathrm{C}$. The scanning electron microscopy used in this research was a Zeiss EVO 50, and the samples for SEM characterisation were taken from the thinner part of the specimens due to uniformity of microstructure, as shown in Figure 2. The samples were successively wet ground with $240,600,800,1200,2500,4000$ grit size papers, and then mechanically polished with $6 \mu, 3 \mu, 1 \mu$ and $0.25 \mu$ diamond paste for $1-2$ minutes in each case. 


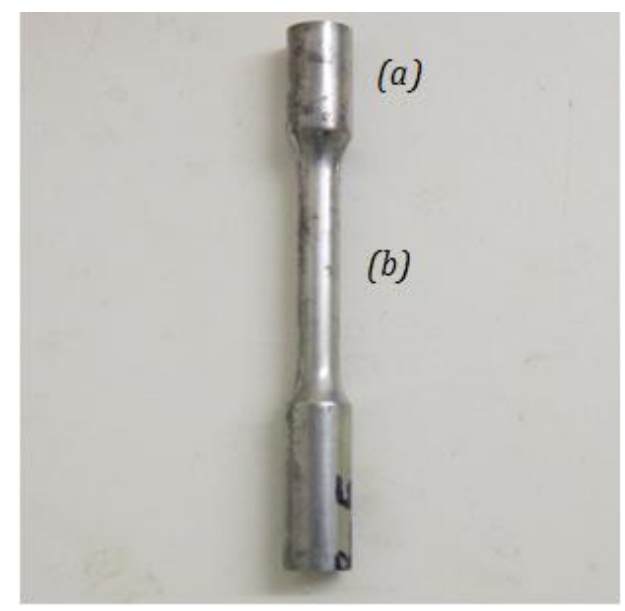

Figure 2. The LM24 specimens made by the BCAST research group. The samples used in SEM characterisation were sectioned from region (b).

Electrochemical noise measurements of the LM24 alloys with various iron levels have been undertaken in solutions with low and high chloride concentrations, specifically $0.06 \mathrm{M}$ and $0.6 \mathrm{M} \mathrm{NaCl}$. Since the samples had very small diameter and were aluminium, it was not possible to use spot welding for making the electrical connection because of its higher electrical and thermal conductivity; hence, the electrical connection was made through a copper wire touching the sample surface as shown in Figure 3. Electrical conductivity between the sample and the copper wire and the cable was measured by an ohmmeter. The resistance between the top surface of the sample and the wire inside the red cable was less than $0.1 \Omega$ (as shown in Figure 3); hence, we could be sure about the electrical conductivity between the sample and copper wire. Afterwards, the sample was embedded in resin and was ready for polishing. Then the samples were polished until the outer copper wire was worn from the surface and the surface of the sample was completely clean of the copper wire. Then the samples were attached to a plastic rod vertically and placed in the solution as shown in Figure 4. A potentiostat and a zero resistance ammeter (ZRA) were used for the measurements. The statistical analysis of the electrochemical noise (EN) data has been done with ECN 1.0 software. ECN Analysis version 1.0 recognises data from various potentiostats. ECN Analysis version 1.0 estimates noise impendence, noise resistance, current power spectral density, potential power spectral density, charge and frequency of corrosion events by statistical and frequency domain methods. It uses both statistical methods and Fast Fourier Transform (FFT) to obtain the time evolution 
of noise impedance, noise resistance, charge and frequency of corrosion events.All results can be viewed and compared directly in ECN Analysis version 1.0 or can be saved for future references and plotting with other software. The method of analysis was time domain to obtain low-frequency noise impedance. The specimens were cut from the middle of the alloy sample after the noise measurements, and prepared for SEM characterization to observe the crosssection of the corroded specimens. The electrochemical noise measurement was repeated for four times, and the results -current and potentials- almost covered each other.
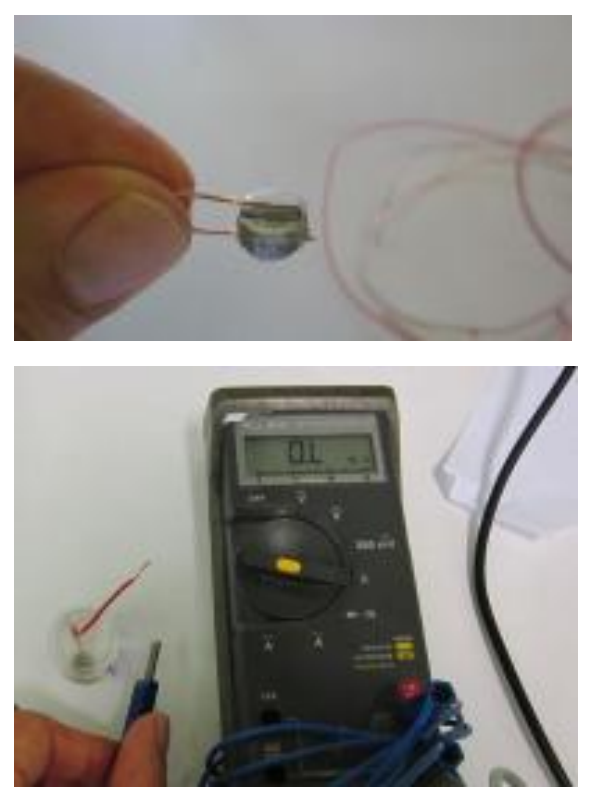

Figure 3. The sample for electrochemical noise and open-circuit and linear sweep measurements.

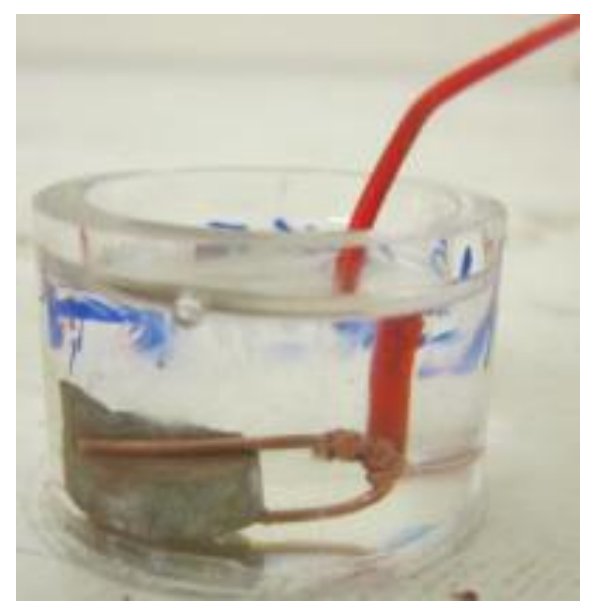

Figure 4. The sample for electrochemical noise and open-circuit and linear sweep measurements. 
The open-circuit and linear sweep measurements were undertaken at room temperature in $0.6 \mathrm{M} \mathrm{NaCl}$ solution. In this experiment, two samples were prepared for each test. The test started from the open-circuit potential and proceeded once in the anodic direction to $1800 \mathrm{mV}$ with two samples and once in the cathodic direction to $-1800 \mathrm{mV}$ with another two samples. The open-circuit measurement lasted for 15 minutes. The data were recorded with a Solartron potentiostat and Modulab software. In both the noise and polarisation measurements, a saturated Calomel electrode (SCE) was used as a reference electrode. Since the presence of corrosion products on the surface did not allow us to observe the pits, copper and iron-rich intermetallic compounds and severity of dissolution of the alloy, the specimens were immersed in nitric acid for 30 seconds to remove all corrosion products and clean the surface for observing corroded surface of the specimen and severity of the corrosion attack after the polarisation measurements then characterized by SEM. In order to avoiding any serious damage of the specimen after polarisation measurements, the specimen had a short contact with nitric acid.

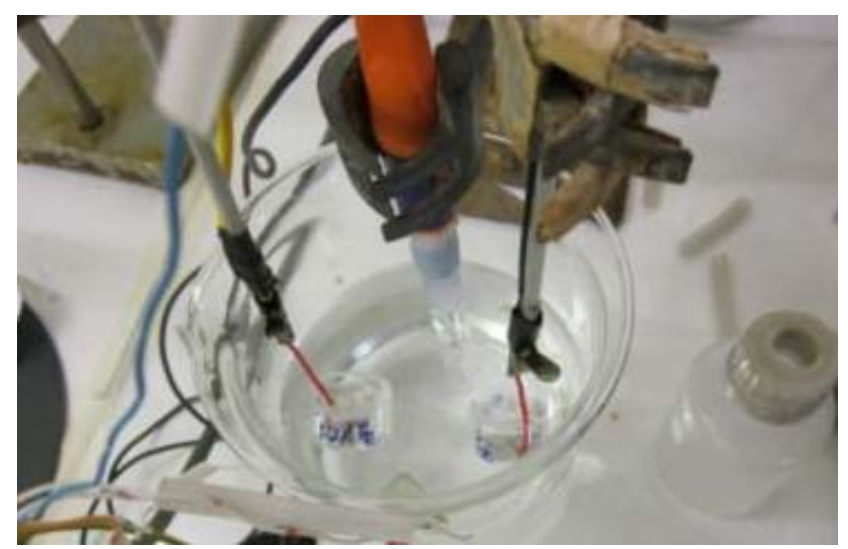

Figure 5. The cell used in electrochemical noise measurement.

The micro-electrochemical characterisation of the specimens was undertaken under ambient conditions by the scanning Kelvin probe force microscopy. Nanoscope software was used for data processing. The topography scan rate was $0.25 \mathrm{~Hz}$, and the images were taken in different scales (from $40 \mu \mathrm{m}$ to $115 \mu \mathrm{m}$ ).

\section{Results:}

- The alloy specifications

As stated previously, the LM24 alloy specimens were made by high-pressure diecasting at BCAST, Brunel University. Table 1 lists the chemical compositions of the 
four as-cast specimens with iron contents ranging from $0.6 \mathrm{wt} \% \mathrm{Fe}$ to $2 \mathrm{wt} \% \mathrm{Fe}$. Additionally, the LM24-0.8Fe contains more copper (4 wt.\% $\mathrm{Cu}$ rather than 3.5 wt.\% $\mathrm{Cu}$ for the other alloys), and the LM24-1.2Fe alloy had an increased manganese level (0.4 wt.\%Mn).

Table 1. Chemical compositions of the LM24 specimens.

\begin{tabular}{|c|c|c|c|c|c|c|c|c|c|}
\hline Sample & $\mathrm{Al}$ & $\mathrm{Si}$ & $\mathrm{Fe}$ & $\mathrm{Cu}$ & $\mathrm{Mn}$ & $\mathrm{Mg}$ & $\mathrm{Zn}$ & $\mathrm{Ti}$ & Others \\
\hline 1 & 84.1 & 8.01 & 1.17 & 3.47 & 0.39 & 0.143 & 2.44 & 0.044 & bal. \\
\hline 2 & 84.5 & 8.14 & 0.603 & 3.48 & 0.287 & 0.226 & 2.45 & 0.040 & bal. \\
\hline 3 & 83.3 & 8.66 & 0.811 & 3.93 & 0.283 & 0.167 & 2.59 & 0.037 & bal. \\
\hline 4 & 82.8 & 8.49 & 2.01 & 3.37 & 0.253 & 0.14 & 2.62 & 0.03 & bal. \\
\hline
\end{tabular}

Figure 6 illustrates the influence of iron content on the mechanical properties of the LM24 specimens. The elongation decreased significantly from $7 \%$ to less than $2 \%$ with increasing iron content, indicating that the alloys with increased iron displayed more brittle behaviour. The UTS and yield strength did not vary markedly with the iron level.

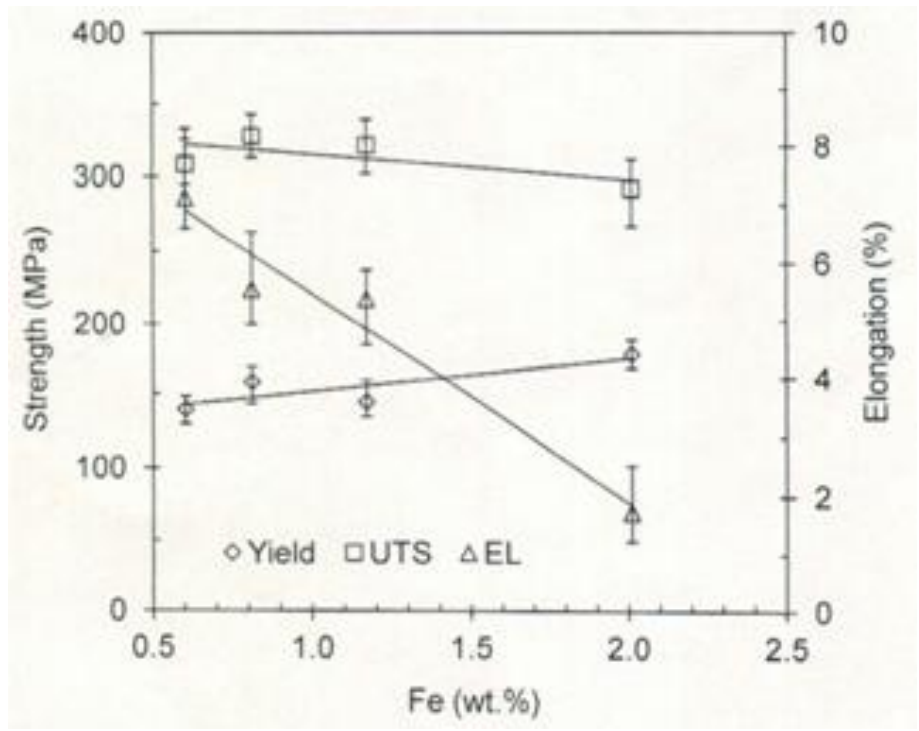

Figure 6. Variation of the mechanical properties of the LM24 alloys with iron content.

\section{- Scanning electron microscopy characterisation with EDX analysis}

Figure 7 illustrates the scanning electron micrographs of the as-cast surface of the alloy LM24 alloys with iron contents from 0.6 wt.\%Fe to 2 wt.\%Fe. According to the EDX analyses listed in Table 2, the iron-rich phases solidified in needle-shaped, star-shaped, blocky form and granular morphologies. With increasing the iron level, the size of the iron-rich phase particles increased, with large $\beta$-AlFeSi 
needles and large $\alpha$-AlFeMnSi star-shaped intermetallic compounds formed in the alloy containing the highest iron concentration ( 2 wt.\%Fe). The blocky form $\alpha$ AlFeMnSi phase solidified in the alloy containing $0.8 \mathrm{wt}$ \%Fe. However, in the alloy containing 1.2 wt.\%Fe, despite the relatively high iron content, granular Febearing intermetallic compounds are observed instead of compounds with larger morphologies (Figure 7-c).

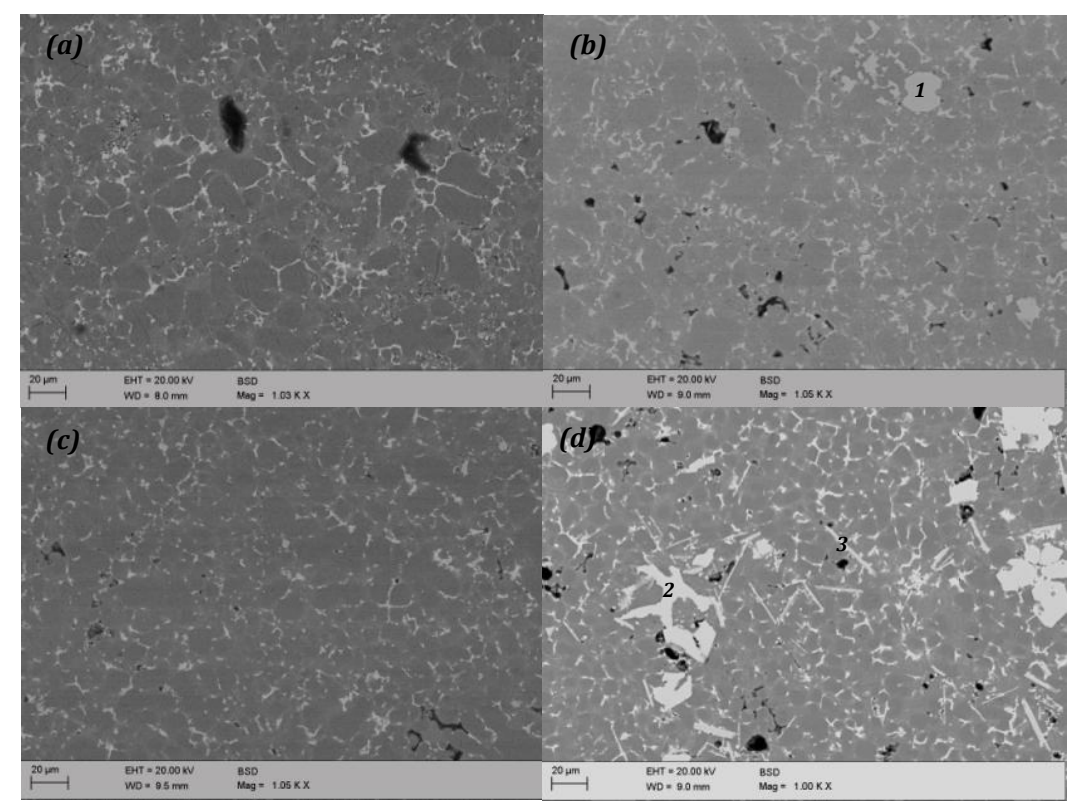

Figure 7. (a) Scanning electron micrograph of the alloy LM24 at various iron concentrations: (a) Al-0.6Fe; (b) Al-0.8Fe; (c) Al-1.2Fe ; (d) Al-2Fe.

Table 2. EDX analyses of the iron-rich phase particles with the different morphologies shown in Figure 7.

\begin{tabular}{|c|l|c|c|c|c|c|c|c|}
\hline Spectrum & \multicolumn{1}{|c|}{ Phase } & $\begin{array}{c}\mathrm{Al} \\
\text { (at.\%) }\end{array}$ & $\begin{array}{c}\mathrm{Si} \\
\text { (at.\%) }\end{array}$ & $\begin{array}{c}\mathrm{Fe} \\
\text { (at.\%) }\end{array}$ & $\begin{array}{c}\mathrm{Mn} \\
\text { (at.\%) }\end{array}$ & $\begin{array}{c}\mathrm{Cu} \\
\text { (at.\%) }\end{array}$ & $\begin{array}{c}\mathrm{Zn} \\
\text { (at.\%) }\end{array}$ & $\begin{array}{c}\mathrm{Cr} \\
\text { (at.\%) }\end{array}$ \\
\hline 1 & $\alpha$-AlFeMnSi & 71.24 & 11.04 & 10.29 & 5.97 & - & - & 1.47 \\
\hline 2 & $\alpha-A l F e M n S i$ & 71.21 & 9.23 & 14.84 & 3.15 & 0.83 & - & 0.75 \\
\hline 3 & $\beta-A l F e S i$ & 68.01 & 17.41 & 12.73 & 0.71 & 0.67 & 0.47 & - \\
\hline
\end{tabular}

In addition to the iron-rich phases, copper-rich intermetallic particles have also been observed in scanning electron micrographs of the as-cast specimens. The $\theta$ $\mathrm{Al}_{2} \mathrm{Cu}$ phases are smaller than the iron-rich phases. Table 3 illustrates the EDX analysis of the copper-rich phase region marked $\mathrm{C}$ in Figure 8. 


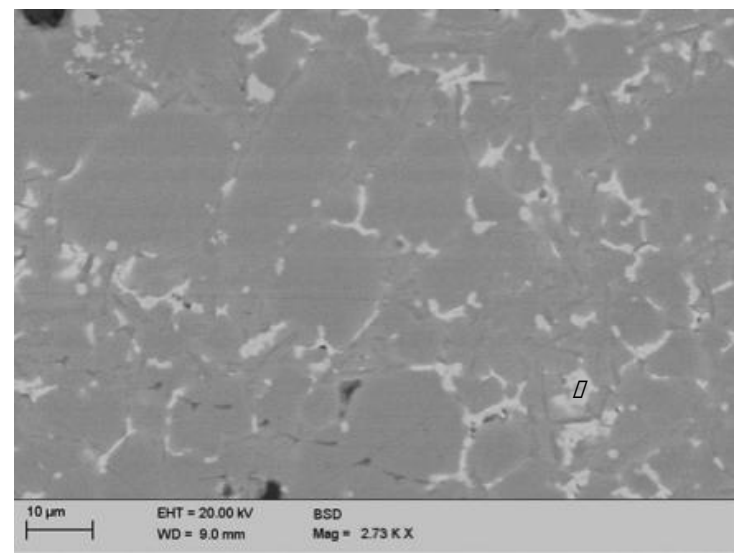

Figure 8. Scanning electron micrographs showing the distribution of the copper-rich phase particles in the LM24 alloy with $0.8 \mathrm{wt} \% \mathrm{Fe}$.

Table 3. EDX analyses of the $\theta-\mathrm{Al}_{2} \mathrm{Cu}$ phase shown in Figure 7.

\begin{tabular}{|c|c|c|c|c|}
\hline Spectrum & Phase & $\begin{array}{c}\mathrm{Al} \\
\text { (at.\%) }\end{array}$ & $\begin{array}{c}\mathrm{Si} \\
\text { (at.\%) }\end{array}$ & $\begin{array}{c}\mathrm{Cu} \\
\text { (at.\%) }\end{array}$ \\
\hline 1 & $\theta-\mathrm{Al}_{2} \mathrm{Cu}$ & 79.03 & 3.65 & 17.32 \\
\hline
\end{tabular}

The $\beta$-AlFeSi phase particles have been identified in electron images of the alloy containing the highest iron concentration ( $2 \mathrm{wt}$.\% Fe); the images were prepared by SEM serial block face sectioning using a GATAN 3View system. Figure 9 displays a series of images of the alloy LM24- 2 wt.\% Fe alloy. The $\theta-\mathrm{Al}_{2} \mathrm{Cu}$ phase particles have been nucleated on some areas of the $\beta$-AlFeSi platelets, as shown in the dashed circle in Figure 9. This phase was distinguishable by its greater brightness in the backscattered electron images than the $\beta$-AlFeSi phase. 


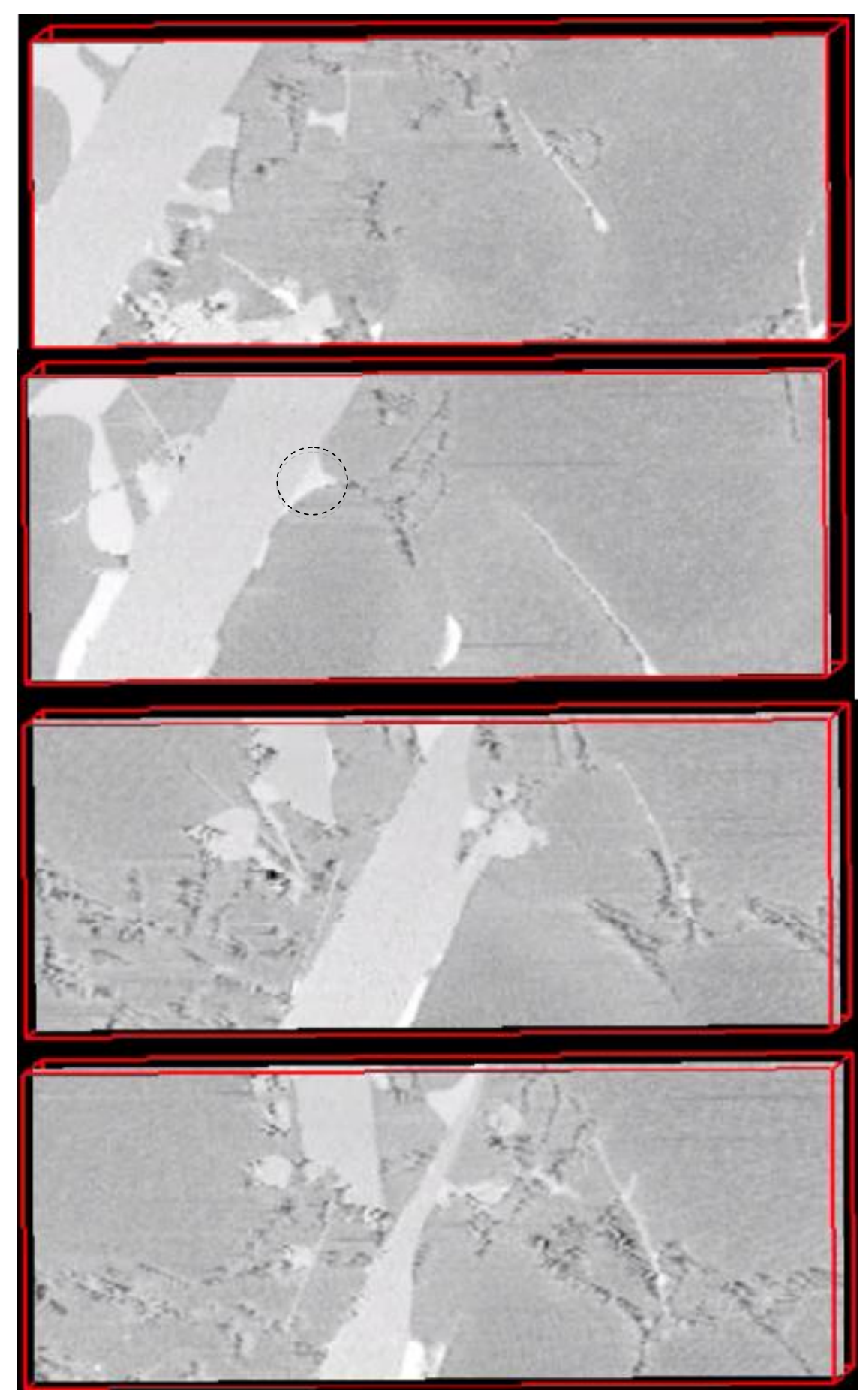

Figure 9. Electron images of the LM24-2 wt.\% Fe alloy. The $\beta$-AlFeSi platelets are displayed in the series of images.

Figure 10 illustrates the $\beta$-AlFeSi phase particles and the large $\alpha$-AlFeSi phase particles in the 3D electron images of the LM24 - 2 wt.\%Fe alloy. As stated previously, the areas of increased brightness contain high copper contents. 


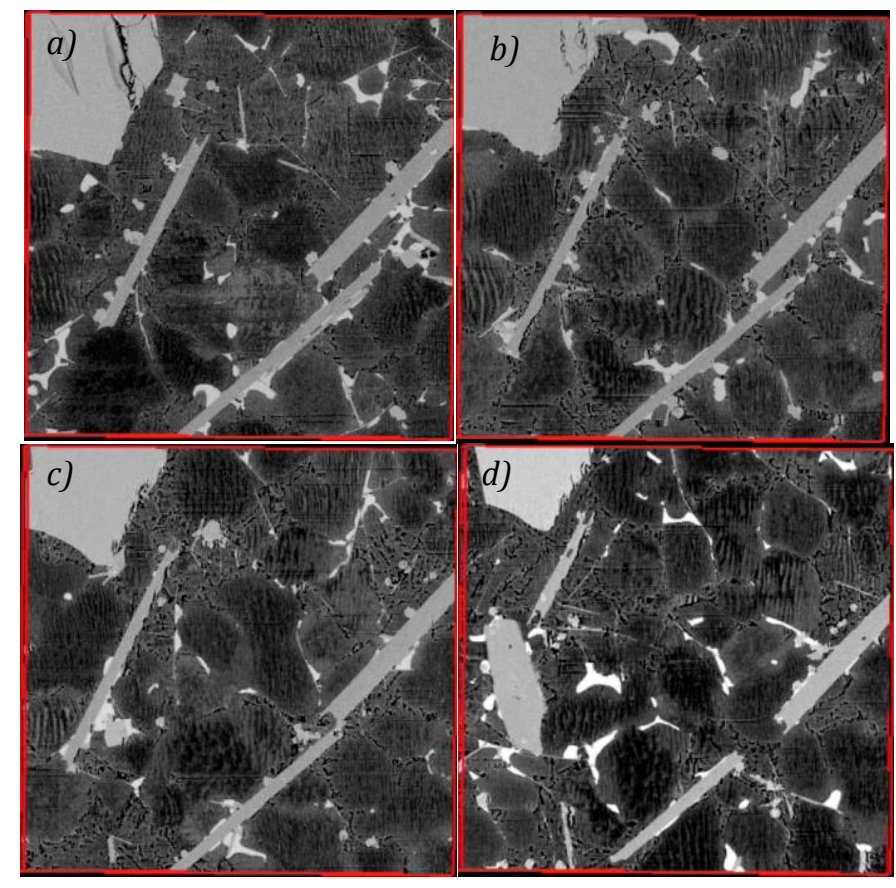

Figure 10. Electron images of LM24- 2 wt.\%Fe alloy. The images have been taken from the bottom of the specimen to the top of the specimen from a to $\mathrm{d}$.

\section{- Electrochemical noise measurement}

Figure 11 llustrates the current and potential time records of the alloys LM24 containing various iron additions during immersion in the low-chloride (a) and the high-chloride (b) solutions. Generally, the LM24-0.8Fe alloy shows the lowest current fluctuations in both solutions compared with the other alloys; however, in some periods, this alloy displays a bit more noisy current than some alloys, for instance, from 75000 seconds onward in $0.06 \mathrm{M} \mathrm{NaCl}$ compared to the LM24-2Fe alloy. The alloy containing the highest iron content ( 2 wt.\% Fe) had a noiseless current during the measurement in the dilute solution; however, the plot shows a fluctuating current from the beginning of immersion in the concentrated solution up to 14 hours and, likewise, the potential is also noisy in this range. At the beginning of the experiment, the LM24 alloy containing the lowest iron level (0.6 wt.\% Fe) experienced severe current fluctuations in the dilute solution, but from 14 hours onward, the current became stable until it displayed a slightly noisy current at the end. However, this alloy had a stable low fluctuation in potentials in both solutions. The alloy containing $1.2 \mathrm{wt}$ \% Fe with the highest manganese level (0.4 wt.\% Mn) showed severe current fluctuations in the concentrated solution; 
however, it had almost similar noise current behaviour to that of the LM24 -0.6 wt.\% Fe alloy in the dilute solution.

a) $0.06 \mathrm{M} \mathrm{NaCl}$

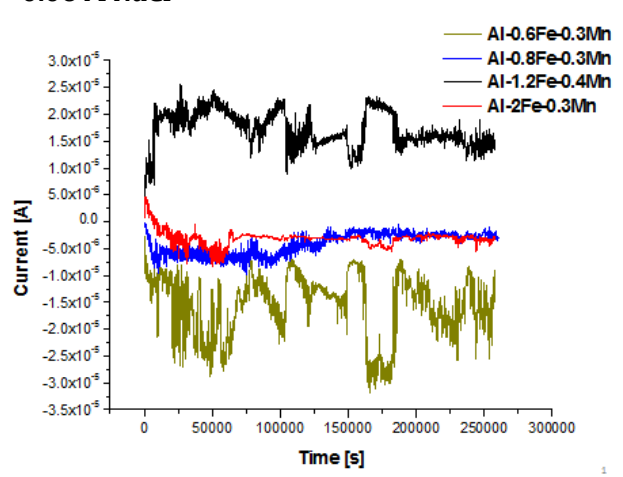

b) $0.6 \mathrm{M} \mathrm{NaCl}$

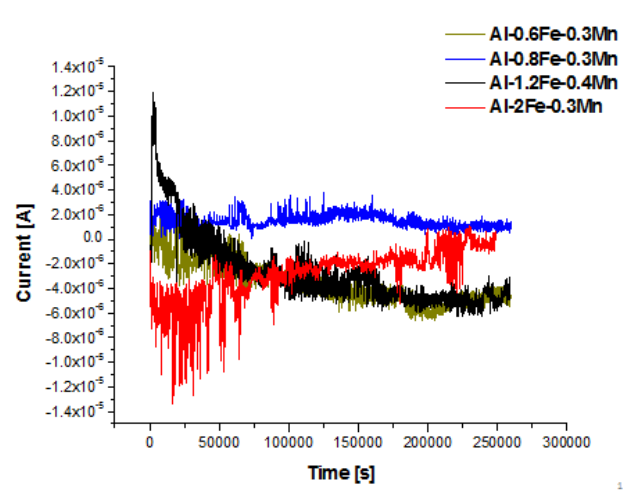

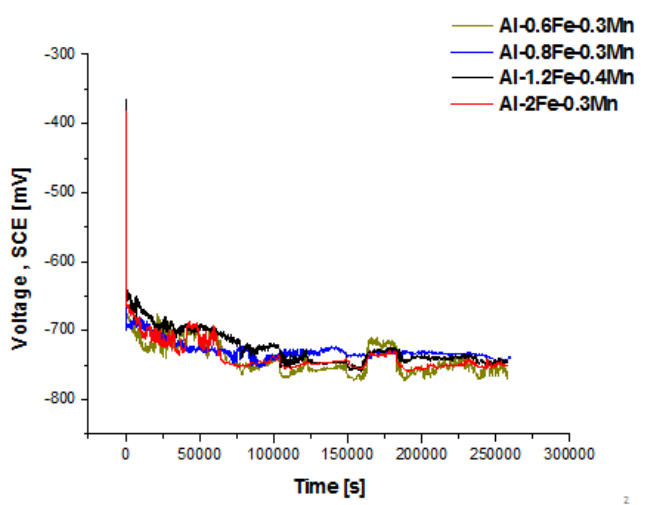

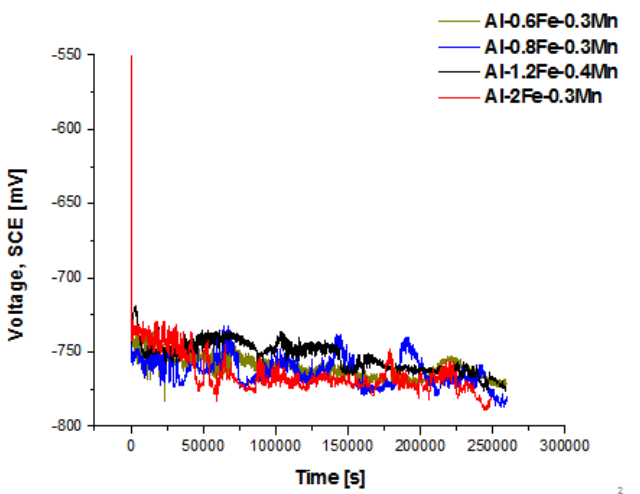

Figure 11. Current and potential time records for LM24 at $0.6 \mathrm{wt} \% \mathrm{Fe}, 0.8 \mathrm{wt} . \% \mathrm{Fe}$, 1.2 wt.\% Fe and 2 wt.\% Fe during immersion in a) $0.06 \mathrm{M} \mathrm{NaCl}$; and b) $0.6 \mathrm{M} \mathrm{NaCl}$.

The effect of iron content on potential-time behaviour of the LM24 alloy was not very significant in both 0.06 and $0.6 \mathrm{M} \mathrm{NaCl}$ solutions. The potentials of the specimens started to decrease from $-650 \mathrm{mV}$ (SCE) up to 28 hours after immersion in $0.06 \mathrm{M} \mathrm{NaCl}$ solution, and then the samples experienced steady potentials close to $-750 \mathrm{mV}$ (SCE). The alloys with $0.6 \mathrm{wt} \% \mathrm{Fe}$ and $2 \mathrm{wt} \% \mathrm{Fe}$ additions had a very similar potential-time behaviour during the immersion in the dilute solution. The highest potentials were recorded for the LM24 - 1.2 wt.\%Fe alloy, except in the time period between $100,000 \mathrm{~s}$ and $150,000 \mathrm{~s}$ when the alloy potential was -750 $\mathrm{mV}$ (SCE), which is less than that of the LM24 - $0.8 \mathrm{wt} \%$ Fe by about $20 \mathrm{mV}$. The potential-time behaviour for the LM24 alloys containing $0.6 \mathrm{wt} . \% \mathrm{Fe}, 1.2 \mathrm{wt} . \% \mathrm{Fe}$ 
and 2 wt.\%Fe contents showed a rapid increase of potential between 160,000 s and $180,000 \mathrm{~s}$. High current fluctuations were observed for the LM24 with the lowest iron content ( 0.6 wt.\%Fe) from the beginning of the experiment up to $50,000 \mathrm{~s}$. This was followed by a rapid increase at $100,000 \mathrm{~s}$, and a slow decrease to $150,000 \mathrm{~s}$. Then the specimen experienced an immediate decrease of the current from $-2.5 \mu \mathrm{A}$ to $-25 \mu \mathrm{A}$ at $160,000 \mathrm{~s}$, followed by a rapid recovery at $180,000 \mathrm{~s}$. The current fluctuation also increased after the immediate decrease after immersion for $200,000 \mathrm{~s}$.

Immersion of the specimens in $0.6 \mathrm{M} \mathrm{NaCl}$ resulted in more potential oscillations compared to the dilute solution. The potential oscillations were much more severe from the initiation of the experiment up to 7 hours for all of the iron additions except 1.2 wt.\%Fe. The LM24 containing 2 wt.\%Fe experienced the lowest potential, close to $-770 \mathrm{mV}$, compared with the other alloys from 7 hours of immersion onward. The highest potentials were recorded for the alloy with 1.2 wt.\%Fe after 7 hours of the experiment. The alloy with 0.8 wt.\%Fe showed four peaks in potential-time behaviour after almost every 50,000 s of immersion.

The current-time plots for the alloys with $0.6 \mathrm{wt} . \% \mathrm{Fe}$ and $1.2 \mathrm{wt} . \% \mathrm{Fe}$ additions overlapped each other in the range of $0 \mu \mathrm{A}$ and $-6 \mu \mathrm{A}$ during immersion in $0.06 \mathrm{M}$ $\mathrm{NaCl}$. However, the alloy containing the higher iron level (1.2 wt.\%Fe) showed severe current fluctuations for the duration of the experiment. The highest current fluctuation, betweem $-4 \mu \mathrm{A}$ and $-13 \mu \mathrm{A}$, was revealed from the initiation of the experiment up to $50,000 \mathrm{~s}$ for the alloy containing the highest iron level (2 $w t . \% \mathrm{Fe}$ ) and then the fluctuations decreased with an increase of the current to the region of $-1 \mu$ A. From 200,000 s onward, the current started to fluctuate between 0 $\mu \mathrm{A}$ and $-4 \mu \mathrm{A}$. The alloy containing $0.8 \mathrm{wt} . \% \mathrm{Fe}$ showed the lowest current fluctuations in the region of $1 \mu \mathrm{A}$ and $2 \mu \mathrm{A}$ during immersion.

Figure 12 illustrates the average charge and the frequency of corrosion events in both $0.06 \mathrm{M}$ and $0.6 \mathrm{M} \mathrm{NaCl}$ solutions. The maximum charge was revealed for the alloy containing the lowest iron addition, $0.6 \mathrm{wt} . \% \mathrm{Fe}$; the charge ranged between $100 \mu \mathrm{C}$ and $1000 \mu \mathrm{C}$ during immersion in the dilute solution. The average charge for the alloy with $2 \mathrm{wt} . \% \mathrm{Fe}$ content fluctuated between $10 \mu \mathrm{C}$ and $100 \mu \mathrm{C}$ from the 
initiation of immersion up to $50,000 \mathrm{~s}$, and then a rapid decrease to $0.2 \mu \mathrm{C}$ was followed by an increase to a peak at $10 \mu \mathrm{C}$, and a slow decrease to $0.07 \mu \mathrm{C}$. From $150,000 \mathrm{~s}$ onward, the average charge increased slowly to $10 \mu \mathrm{C}$ again. This alloy showed the lowest charge in the time period between $50,000 \mathrm{~s}$ and $150,000 \mathrm{~s}$. The alloys with 0.8 wt.\%Fe and 1.2 wt.\%Fe additions showed the average charge between $1 \mu \mathrm{C}$ and $100 \mu \mathrm{C}$. The higher charge fluctuation was revealed for the LM24 - 1.2 wt.\%Fe alloy with several peaks, and the highest charge occurred in the region of $100,000 \mathrm{~s}$ followed by a rapid decrease up to $125,000 \mathrm{~s}$ and, subsequently, a rapid recovery was recorded. The average frequency of the alloys containing 0.6 wt.\%Fe and 2 wt.\%Fe was revealed between $0.02 \mathrm{~Hz}$ and $0.1 \mathrm{~Hz}$, which is lower than that of other alloys for the duration in the dilute solution. The average charge of the corrosion events is very similar for the alloys containing 0.8 wt.\%Fe and 1.2 wt.\%Fe during immersion in $0.6 \mathrm{M} \mathrm{NaCl}$ which was in the same range recorded for these alloys immersed in the dilute solution $(1 \mu \mathrm{C}-100 \mu \mathrm{C})$. The other two alloys showed the highest charge by $200 \mu \mathrm{C}$ at the initiation of immersion in $0.6 \mathrm{M} \mathrm{NaCl}$ solution. The charge was followed by a rapid decrease to $1 \mu \mathrm{C}$ up to $100,000 \mathrm{~s}$ for these alloys. From $150,000 \mathrm{~s}$ onward, the alloy containing the highest iron level showed the highest charge, and the alloy containing the lowest iron content showed the lowest charge.

The frequency of corrosion events in $0.06 \mathrm{M} \mathrm{NaCl}$ was recorded in the range of $0.01 \mathrm{~Hz}-100 \mathrm{~Hz}$ that was a wider range compared to the recorded frequency by immersion in the concentrated solution. From the initiation of the measurement up to $50,000 \mathrm{~s}$, the LM24 alloy containing $0.6 \mathrm{wt}$.\%Fe and $2 \mathrm{wt} . \% \mathrm{Fe}$ showed the lowest frequency. Subsequently, the frequency increased rapidly with a fluctuation below $3 \mathrm{~Hz}$ for the LM24 - 0.6 wt.\%Fe alloy and a fluctuation above $2 \mathrm{~Hz}$ for the LM24 - 2 wt.\%Fe alloy. The frequency time records for the alloy containing 0.8 wt.\%Fe showed a narrow range up to $100,000 \mathrm{~s}$, followed by a slow increase with a fluctuation in the region of $2 \mathrm{~Hz}-10 \mathrm{~Hz}$. A similar frequency-time behaviour up to $100,000 \mathrm{~s}$ was revealed for the alloy with $1.2 \mathrm{wt}$.\%Fe addition. It was followed by a rapid increase to the region close to $10 \mathrm{~Hz}$ and a slow decrease to the vicinity of 1 $\mathrm{Hz}$. 

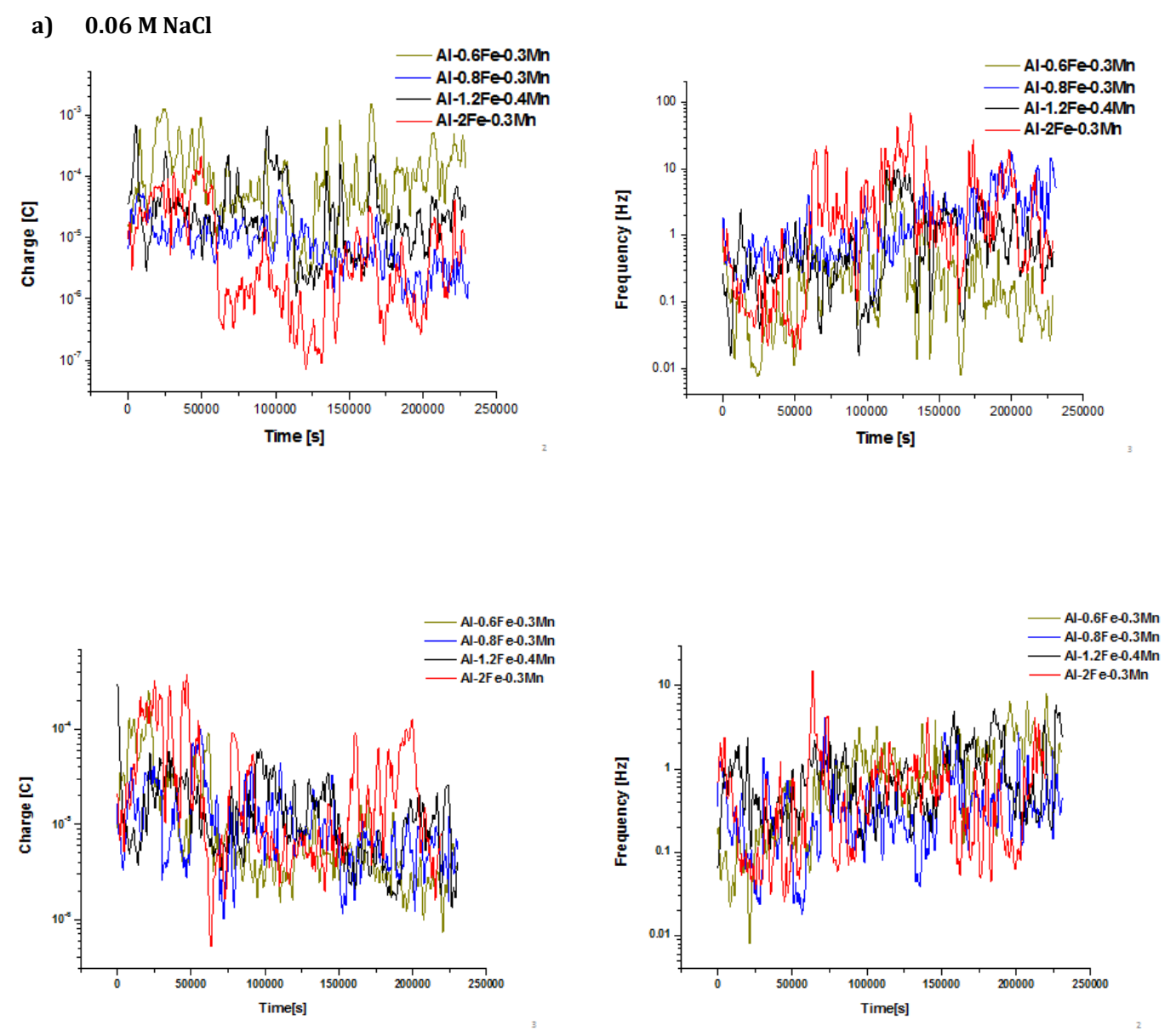

Figure 12. The average charge and frequency of the LM24 at various iron levels $(0.6$, $0.8,1.2$ and 2 wt.\% Fe) in: a) $0.06 \mathrm{M} \mathrm{NaCl}$; and b) $0.6 \mathrm{M} \mathrm{NaCl}$.

Figure 13 displays the average noise impedance for immersion of the LM24 alloys with iron additions in $0.06 \mathrm{M} \mathrm{NaCl}$ and $0.6 \mathrm{M} \mathrm{NaCl}$ solutions. The noise impedance in the dilute solution increased with iron additions, except for the alloy containing 1.2 wt.\%Fe that showed a lower noise impedance than the LM24 - 0.8 wt.\%Fe alloy in some regions. The noise impedance for the LM24 - 2wt.\%Fe alloy fluctuated between $5 \mathrm{k} \Omega \cdot \mathrm{cm}^{2}$ and $10 \mathrm{k} \Omega \cdot \mathrm{cm}^{2}$ during immersion, and it started to decrease from 125,000 s onward. The average noise impedance fluctuated between $2 \mathrm{k} \Omega \cdot \mathrm{cm}^{2}$ and $5 \mathrm{k} \Omega . \mathrm{cm}^{2}$ for the alloy containing $0.8 \mathrm{wt} . \% \mathrm{Fe}$ during immersion in $0.06 \mathrm{M} \mathrm{NaCl}$ solution. Similar fluctuations were revealed for the alloy with 1.2 wt.\% iron content; however, this alloy showed the smaller average noise impedance in most regions except in the small region close to 50,000s and 150,000 s. 

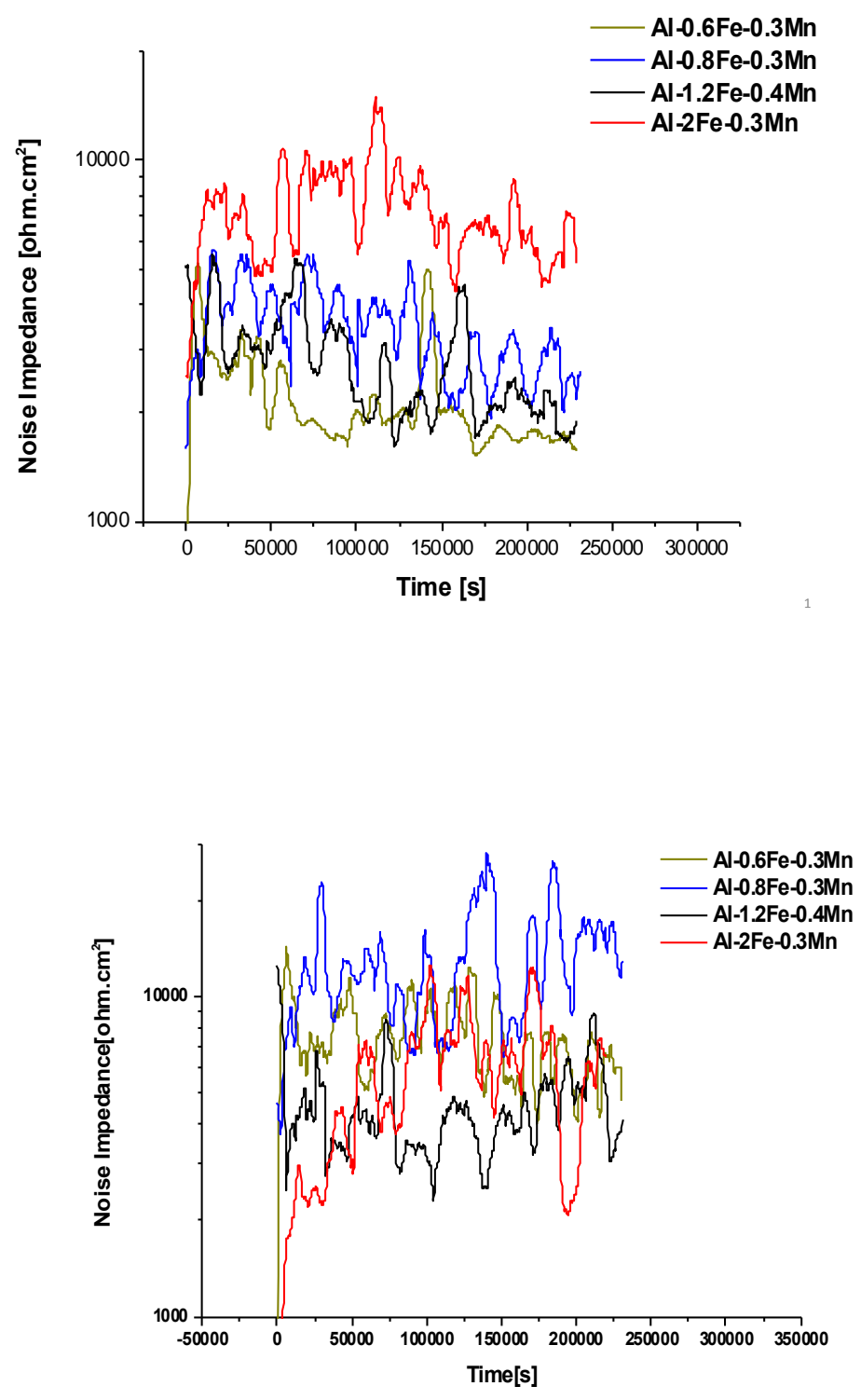

Figure 13. The electrochemical noise impedance of the LM24 alloy with $0.6 \mathrm{wt} \% \mathrm{Fe}$, 0.8 wt.\% Fe, 1.2 wt.\% Fe and 2 wt.\% Fe contents in: a) $0.06 \mathrm{M} \mathrm{NaCl}$; and b) $0.6 \mathrm{M}$ $\mathrm{NaCl}$ solutions.

The lowest noise impedance was observed for the LM24 alloy containing 0.8 wt.\%Fe; the impedance was in the range of $2 \mathrm{k} \Omega . \mathrm{cm}^{2}$ and $3 \mathrm{k} \Omega . \mathrm{cm}^{2}$, with two peaks 
at the commencement of immersion and close to 150,000s. From 150,000s onward, the average noise impedance became more steady at close to $1 \mathrm{k} \Omega . \mathrm{cm}^{2}$.

The average noise impedance for the LM24 alloy showed different noise impedance-time behaviour following immersion in $0.6 \mathrm{M} \mathrm{NaCl}$ solution compared to $0.06 \mathrm{M} \mathrm{NaCl}$ solution. The alloys containing the higher iron additives, $1.2 \mathrm{wt} . \% \mathrm{Fe}$ and 2 wt.\%Fe, showed lower noise impedances from the initiation of the immersion up to 50,000s. It was followed by an increasing trend for the LM24-2 wt.\%Fe alloy from $1 \mathrm{k} \Omega . \mathrm{cm}^{2}$ to $10 \mathrm{k} \Omega . \mathrm{cm}^{2}$. The average noise impedance for the alloy with 0.6 wt.\%Fe started from $10 \mathrm{k} \Omega . \mathrm{cm}^{2}$ and, subsequently, the trend decreased with fluctuations between $5 \mathrm{k} \Omega \cdot \mathrm{cm}^{2}$ and $10 \mathrm{k} \Omega \cdot \mathrm{cm}^{2}$. The highest noise impedance-time behaviour was recorded for the alloy containing $0.8 \mathrm{wt}$.\%Fe with peaks higher than $10 \mathrm{k} \Omega \cdot \mathrm{cm}^{2}$ up to $20 \mathrm{k} \Omega . \mathrm{cm}^{2}$ close to $150,000 \mathrm{~s}$ and 200,000s. From 150,000s onward, the noise impedance plots for the alloys containing 0.6 wt.\%Fe, 1.2 wt.\%Fe and 2 wt.\%Fe became closer to each other in the region between $3 \mathrm{k} \Omega . \mathrm{cm}^{2}$ and $7 \mathrm{k} \Omega . \mathrm{cm}^{2}$.

Figure 14 displays the backscattered scanning electron micrographs of the specimens after immersion in $0.6 \mathrm{M} \mathrm{NaCl}$ solution. The images were taken from the cross-sections of the corroded specimens. 


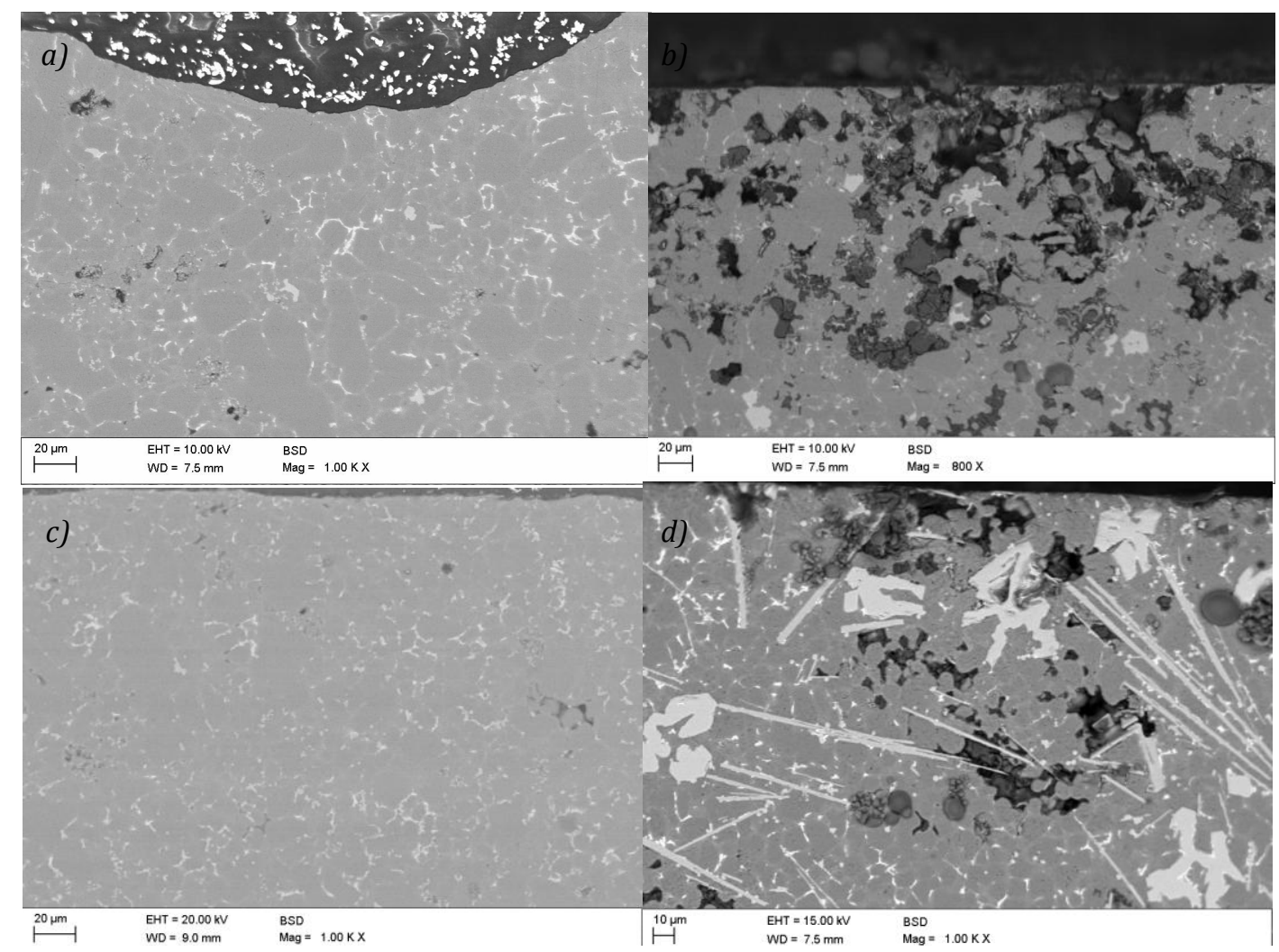

Figure 14. Scanning electron micrographs of the LM24 alloy specimens with different iron contents after immersion in $0.6 \mathrm{M} \mathrm{NaCl}$ solution; a) LM24-0.6Fe; b) LM24-0.8Fe; c) LM24-1.2Fe; d)LM24-2Fe.

The corrosion products were identified by their grey appearance, and shown in the micrographs of the LM24 alloys containing $0.8 \mathrm{wt} . \% \mathrm{Fe}$ and $2 \mathrm{wt} \% \mathrm{Fe}$. There were two types of corrosion products, with aluminium chloride having grey bubble morphologies and aluminium and/or silicon oxide. These products were dispersed on or near the iron-rich phases in both alloys. The corrosion products were not revealed at far distances from the surface of the LM24 alloy containing $0.6 \mathrm{wt} . \% \mathrm{Fe}$ and 1.2 wt. $\%$ Fe.

Figure 15 displays the grain boundaries revealed due to immersion of the LM24 alloy with 0.6 wt.\%Fe, 1.2 wt.\%Fe and 2 wt.\%Fe contents in $0.6 \mathrm{M} \mathrm{NaCl}$ solutions. The grains, highlighted by the circles, were hexagonal. 


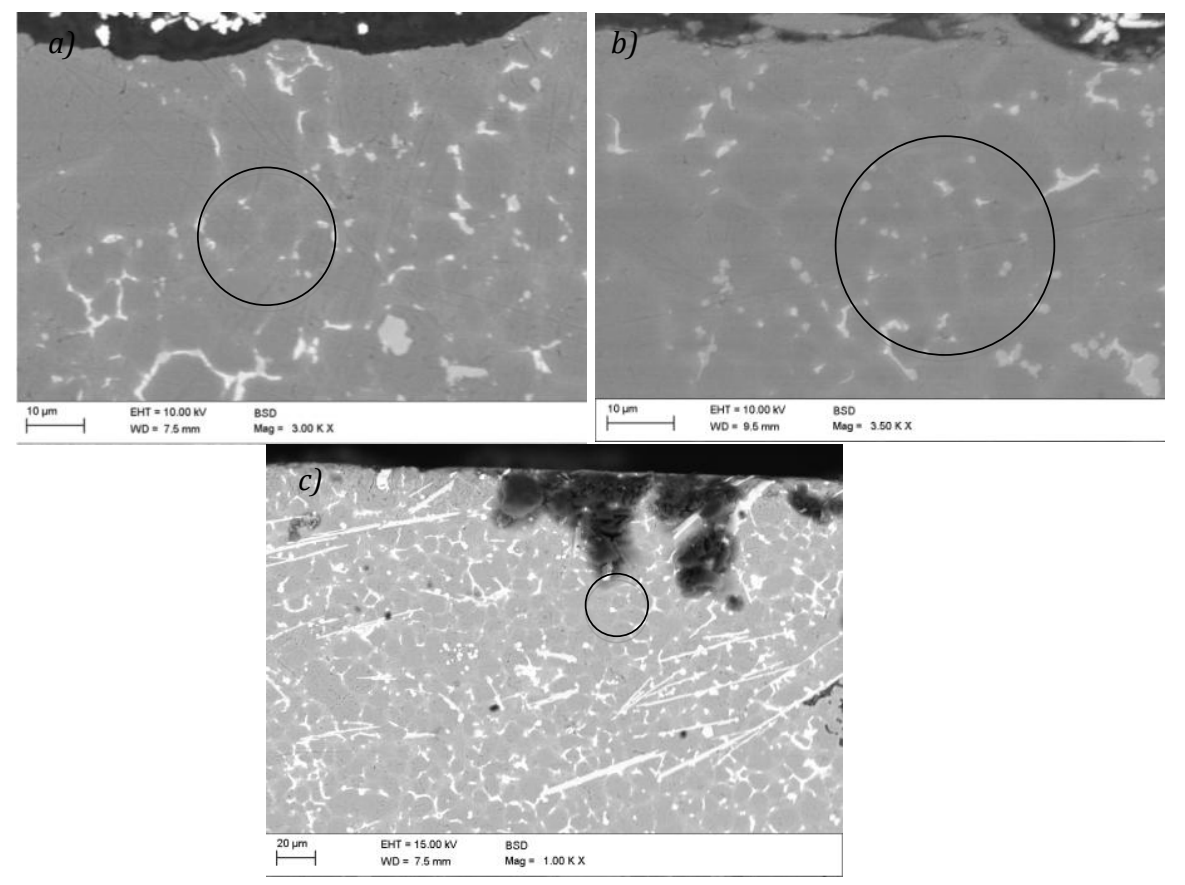

Figure 15. The hexagonal grains shown by the revealed grain boundaries after the noise measurements of the LM24 alloys with different iron contents: a) $0.6 \mathrm{wt} . \% \mathrm{Fe}$; b) 1.2 wt.\%Fe and c) 2 wt.\%Fe in $0.6 \mathrm{M} \mathrm{NaCl}$ solution.

Scanning electron micrographs of top views of the LM24- 0.8Fe, and LM24-1.2Fe alloy specimens are displayed in Figure 16. The images were taken after the noise measurements in $0.6 \mathrm{M} \mathrm{NaCl}$ solution. The corrosion products were aluminium and silicon oxide as identified by the EDX analyses shown in Table 4. 

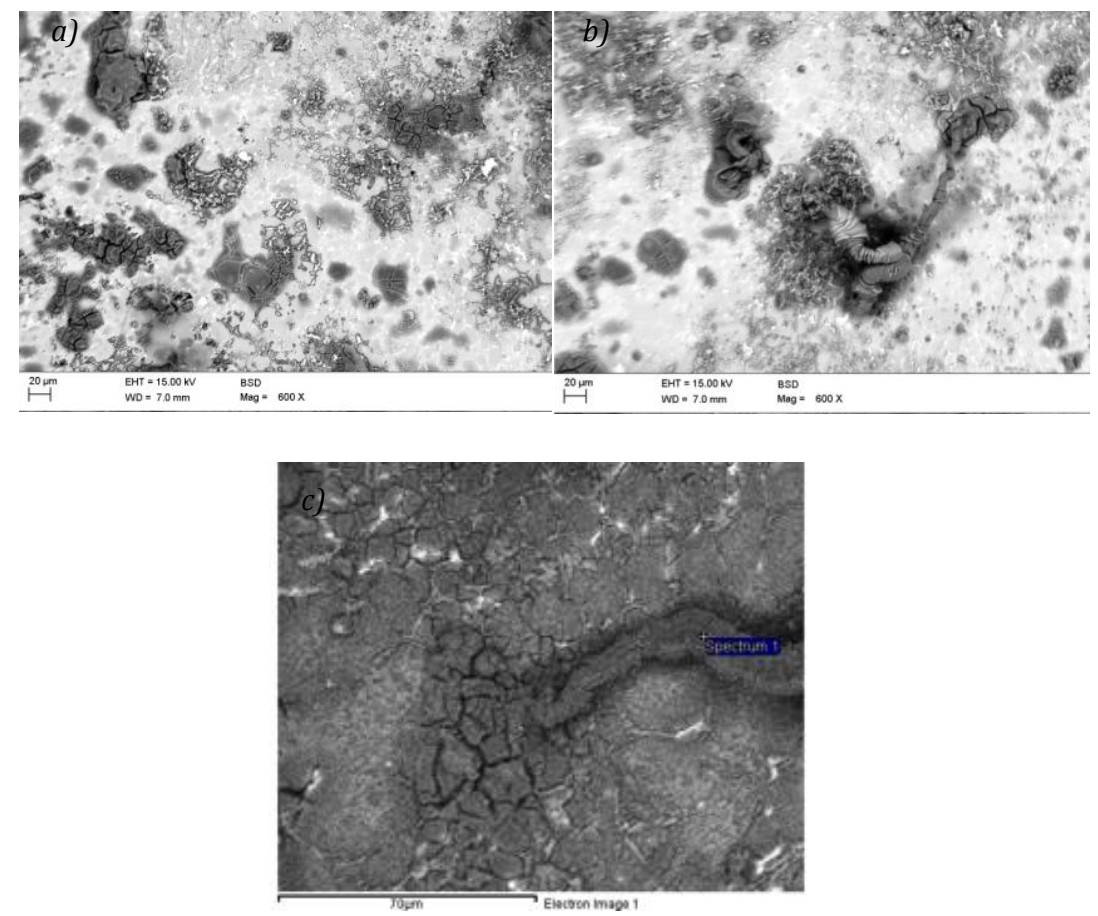

Figure 16. Scanning electron micrographs of top views of the LM24 alloy with different iron contents: a,b) 1.2 wt.\%Fe; and c) 0.8 wt.\%Fe.

Scanning electron micrographs of the top views of the LM24 alloy with 0.6 wt.\%Fe, 0.8 wt.\%Fe, and 1.2 wt.\%Fe contents after immersion in $0.6 \mathrm{M} \mathrm{NaCl}$ solution are displayed in Figure 17. The aluminium and silicon oxides were formed on the top surfaces of the LM24 alloy samples.

Table 4. EDX analyses of the corrosion products formed on the top surface of the LM24 alloy after noise measurement in $0.6 \mathrm{M} \mathrm{NaCl}$ solution.

\begin{tabular}{|c|c|c|c|c|c|}
\hline Spectrum & Phase & $\begin{array}{c}\text { O } \\
\text { (at.\%) }\end{array}$ & $\begin{array}{c}\mathrm{Al} \\
\text { (at.\%) }\end{array}$ & $\begin{array}{c}\text { Si } \\
\text { (at.\%) }\end{array}$ & $\begin{array}{c}\mathrm{Cl} \\
\text { (at.\%) }\end{array}$ \\
\hline 1 & $\begin{array}{c}\text { Corrosion } \\
\text { products }\end{array}$ & 68.21 & 28.03 & 1.29 & 2.47 \\
\hline
\end{tabular}

- Electrochemical polarisation measurement

Figure 18 illustrates the E-logi plots of the LM24 alloys with 0.6 wt.\%Fe, 0.8 wt.\%Fe, 1.2 wt.\%Fe and 2 wt.\%Fe contents in $0.06 \mathrm{M} \mathrm{NaCl}$ and $0.6 \mathrm{M} \mathrm{NaCl}$ electrolytes. 
The potentials and currents of the LM24 alloy did not vary with the iron level in both $0.06 \mathrm{M} \mathrm{NaCl}$ and $0.6 \mathrm{M} \mathrm{NaCl}$ solutions.

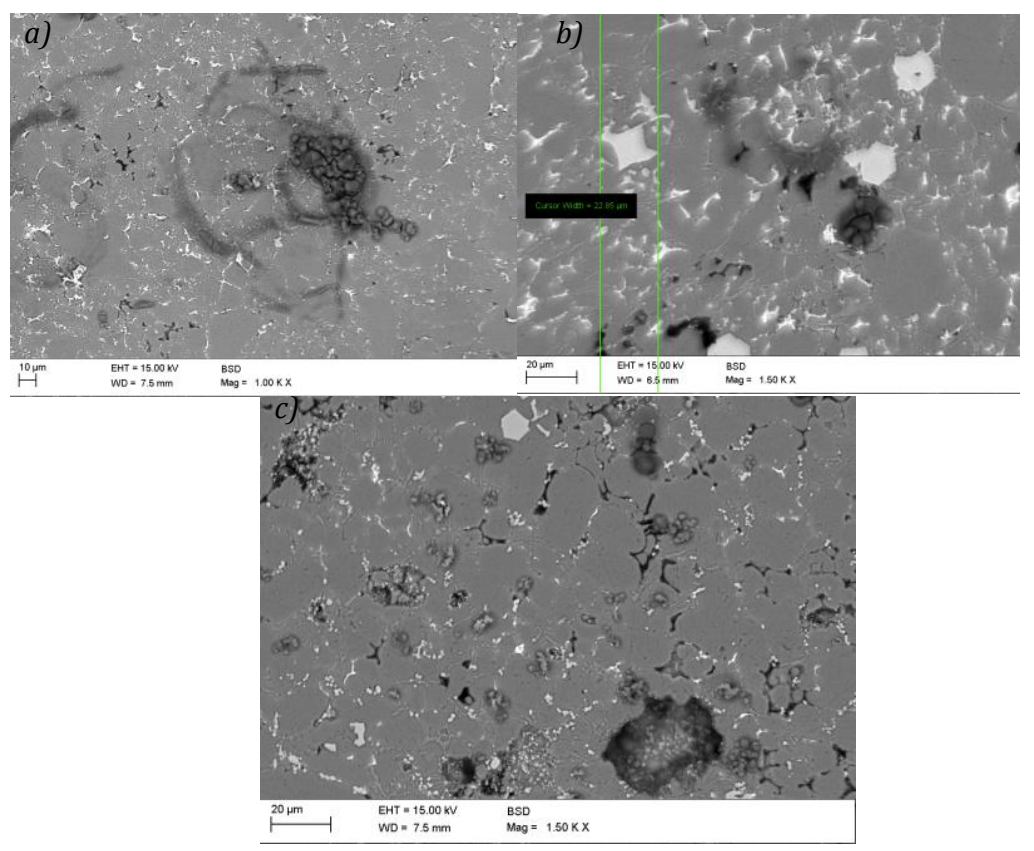

Figure 17. The top view scanning electron micrographs of the LM24 alloy with different iron contents: a) 0.6 wt.\%Fe; b) 08 wt.\%Fe and c) 1.2 wt.\%Fe after immersion in $0.6 \mathrm{M} \mathrm{NaCl}$ solution.

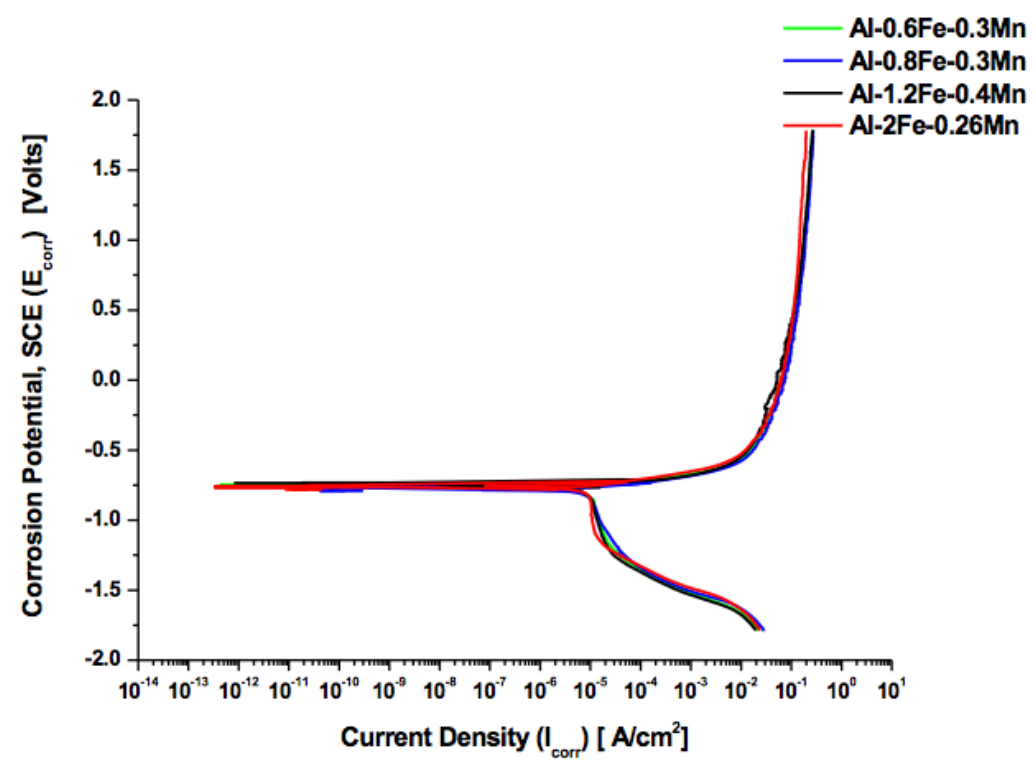

Figure 18. The electrochemical polarisation plots of E-logi for the LM24 alloy with 0.6 wt.\%Fe, 0.8 wt.\%Fe, 1.2 wt.\%Fe and 2 wt.\%Fe contents in a) $0.06 \mathrm{M} \mathrm{NaCl}$; and b) $0.6 \mathrm{M} \mathrm{NaCl}$. 
Scanning electron micrographs of the top views of the LM24 alloy specimens used for the anodic polarisation measurements are shown in Figure 19. The iron-rich phases had a kite-shaped or blocky-form, with a width of $23 \mu \mathrm{m}$ in the LM24 alloy containing $0.8 \mathrm{wt} . \% \mathrm{Fe}$ as shown in Figure 18. The aluminium oxides had bubbleshaped or worm-shaped morphologies after immersion in $0.6 \mathrm{M} \mathrm{NaCl}$ solution.
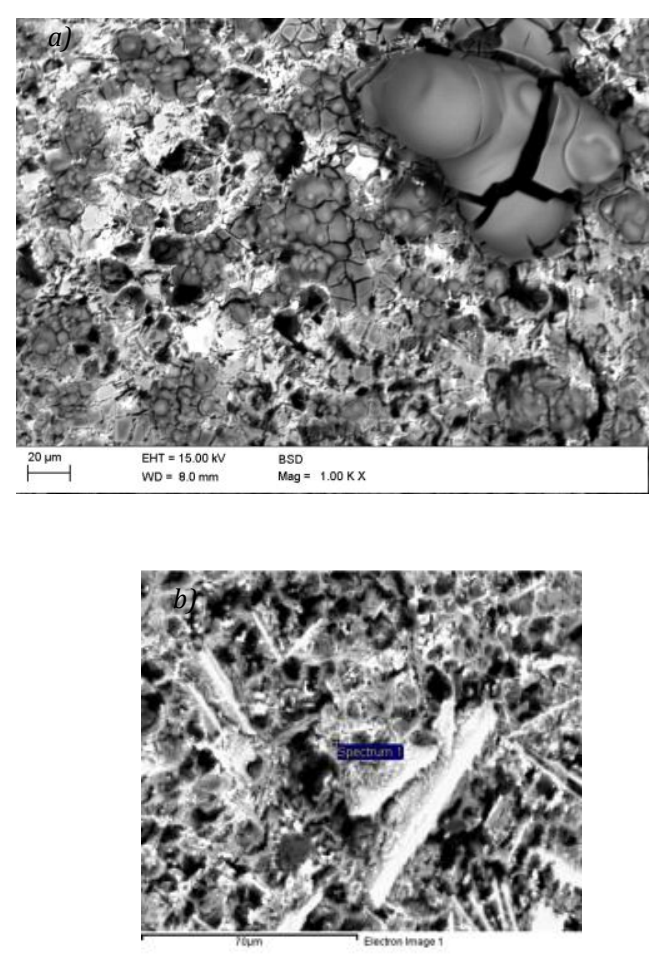

Figure 19. Scanning electron micrographs of top views of the LM24 alloy with different iron contents: a) $0.8 \mathrm{wt} . \% \mathrm{Fe}$; and b) $2 \mathrm{wt} . \% \mathrm{Fe}$ after anodic polarisation in $0.6 \mathrm{M} \mathrm{NaCl}$ electrolyte.

The specimens were damaged more seriously after the anodic polarisation measurement than the cathodic measurement. Pits were revealed in the characterisation of the corroded samples, and the silicon concentration was much higher than aluminium from the EDX analyses reported in Table 5.

Table 5. EDX analyses of the LM24-2Fe alloy specimens after anodic polarisation measurement in $0.6 \mathrm{M} \mathrm{NaCl}$ solution.

\begin{tabular}{|c|c|c|c|c|c|c|}
\hline Spectrum & Phase & $\begin{array}{c}\mathrm{O} \\
\text { (at.\%) }\end{array}$ & $\begin{array}{c}\mathrm{Al} \\
\text { (at.\%) }\end{array}$ & $\begin{array}{c}\mathrm{Si} \\
\text { (at.\%) }\end{array}$ & $\begin{array}{c}\mathrm{Fe} \\
\text { (at.\%) }\end{array}$ & $\begin{array}{c}\mathrm{Cu} \\
\text { (at.\%) }\end{array}$ \\
\hline 1 & Matrix & 14.61 & 15.25 & 63.76 & 2.56 & 3.82 \\
\hline
\end{tabular}




\section{- Scanning Kelvin probe force microscopy}

Figure 20 illustrates the potential maps of the LM24 alloys with different iron additions. The Volta surface potentials depended on the type of phases identified in the scanning electron micrographs.

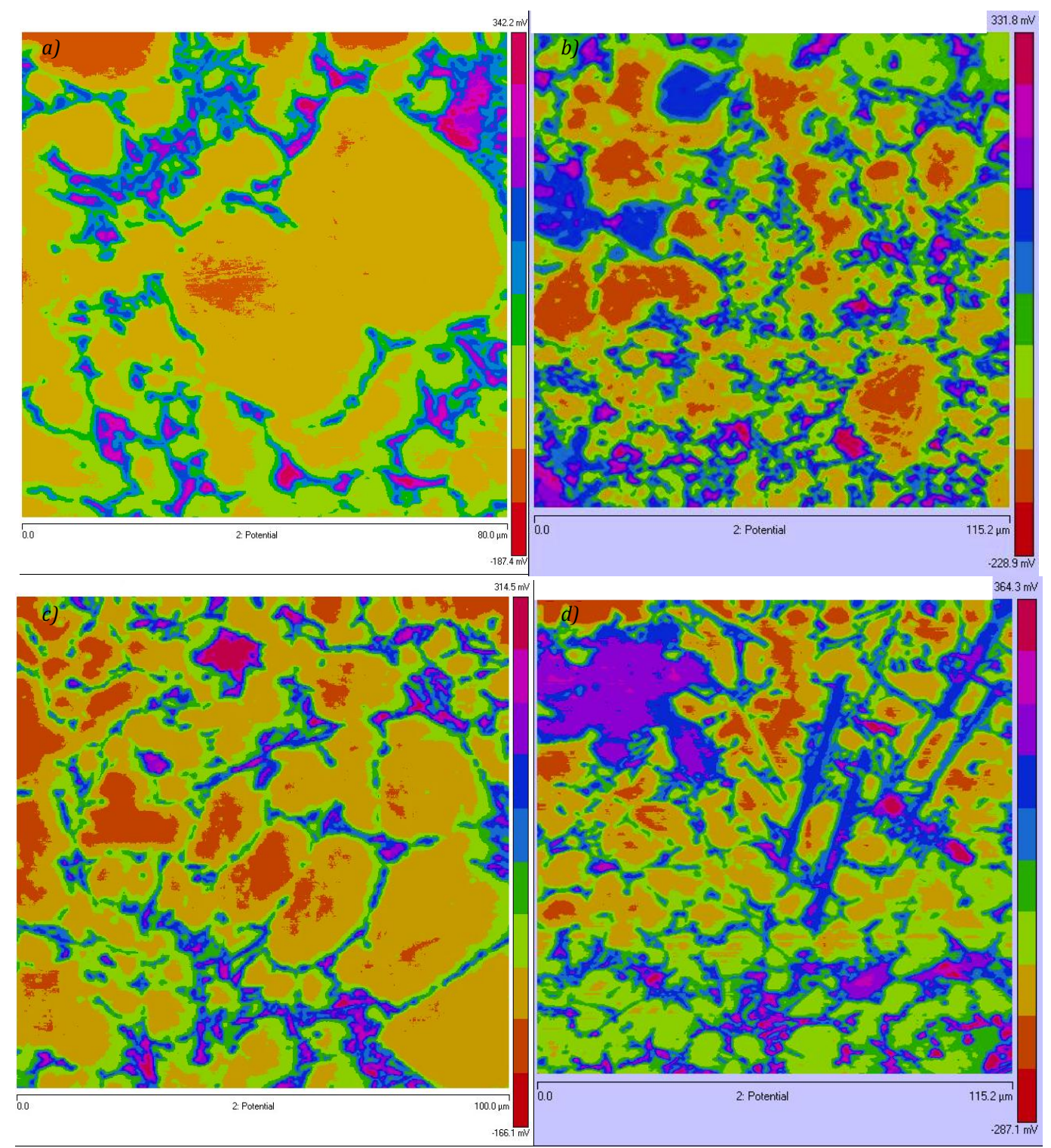

Figure 20. The potential maps for the LM24 alloys with different iron contents: a) 0.6 wt.\%Fe; b) 0.8 wt.\%Fe; c) 1.2 wt.\%Fe; and d) 2 wt.\%Fe.

The phases shown in blue colour that had the potentials between $110-160 \mathrm{mV}$ were distributed significantly in the LM24-0.8Fe alloy. According to the EDX analyses, these phases are attributed to the iron-rich phases, especially with the larger morphologies. However, the centre regions of the phases were darker and, in most cases it became dark pink which showed the potentials close to 250-300 
$\mathrm{mV}$, and may contain $\theta-\mathrm{Al}_{2} \mathrm{Cu}$ since copper has a high surface potential. The similar potential boundaries were revealed in the potential maps of the other alloys; however, the phases were narrow and less distributed in the LM24-0.6Fe and LM24-1.2Fe alloys. Hence, the larger areas with low potential were confined by these phases; consequently, the potential gradient increased for these alloys rather than the LM24-0.8Fe alloy. Whilst the potential map of the LM24 alloy containing 2 wt.\%Fe was very similar to that of the LM24-0.8Fe alloy, larger surface areas with a potential range of $100-150 \mathrm{mV}$ were revealed in the potential map of this alloy due to presence of the larger iron-rich phases ( $\alpha$-AlFeMnSi and $\beta$-AlFeSi) compared to the LM24-0.8Fe alloy. However, these areas had lower surface potentials than the copper-rich phases shown in pink in the potential maps.
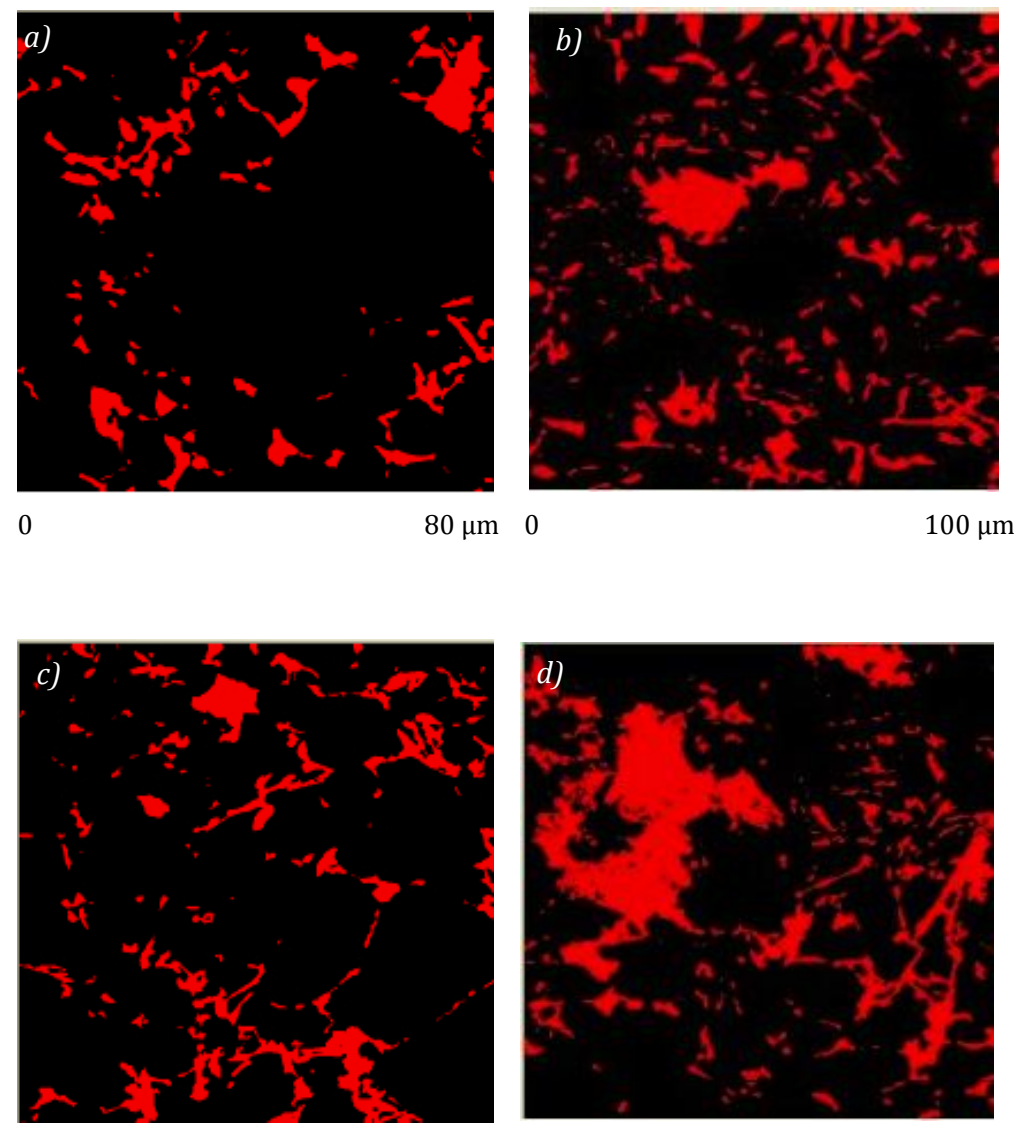

0

$100 \mu \mathrm{m} 0$

$100 \mu \mathrm{m}$

Figure 21. The flooding images of potential maps for the LM24 alloys with different iron contents: a) $0.6 \mathrm{wt}$.\%Fe in $80 \mu \mathrm{m}$ scale; b) $0.8 \mathrm{wt} . \% \mathrm{Fe}$ in $100 \mu \mathrm{m}$ scale; c) 1.2 wt.\%Fe in $100 \mu \mathrm{m}$ scale; and d) 2 wt.\%Fe in $100 \mu \mathrm{m}$ scale. The red areas show the surfaces with potentials higher than $150 \mathrm{mV}$. 
Figure 21 shows the flooding images of the potential maps for the LM24 alloy specimens at the given scales. The red areas illustrate the surfaces with potentials higher than $150 \mathrm{mV}$. Although the minimum and maximum of total areas of the red regions were observed in potential maps of the LM24-0.6Fe and LM24-2Fe alloys respectively, the high potential areas did not vary with iron level in the LM24$0.8 \mathrm{Fe}$ and LM24-1.2Fe alloys significantly.

Figure 22 shows the sectioning in the potential maps of the LM24 alloy specimens. The distribution of the intermetallic phases was higher in the LM24-0.8Fe and LM24-2Fe alloys rather than the other alloys. Narrow intermetallic phases were observed in the LM24-0.6Fe and LM24-1.2Fe alloys. The lightest points in the image showed the peaks of surface potentials around 600-700 $\mathrm{mV}$. 

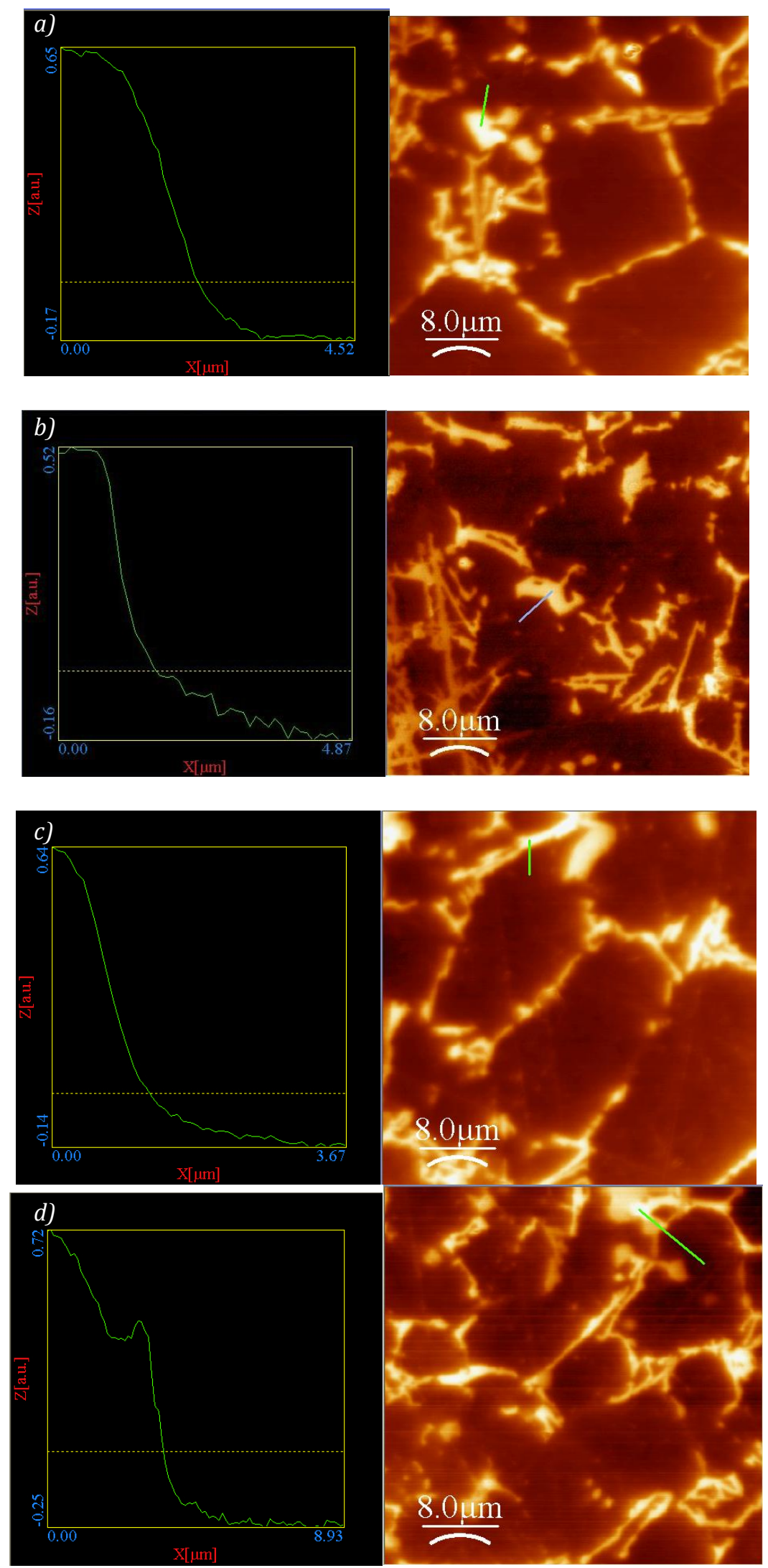

Figure 22. The sectioning of the potential maps for the LM24 alloys with different iron contents: a) 0.6 wt.\%Fe; b) 0.8 wt.\%Fe; c) 1.2 wt.\%Fe; and d) 2 wt.\%Fe. 


\section{Discussion:}

According to Taylor [12] the iron level required for formation of the $\beta$-AlFeSi platelets in aluminium alloys must exceed the critical iron concentration which is 0.6 wt.\%Fe for the LM24 alloy. Although the iron contents were higher than this level in all of the specimens, the formation of the $\beta-\mathrm{Al}_{5} \mathrm{FeSi}$ platelets was eliminated due to the presence of manganese in the alloy composition except for the LM24-2Fe alloy with lower manganese concentration $(0.26$ wt.\% compared to 0.3 wt.\%), and a much higher iron concentration than the critical value. Formation of the large iron-rich intermetallic compounds is desirable with iron concentration. Likewise, although it was expected to observe the large iron-rich phases in the LM24-1.2Fe alloy, the presence of a higher manganese concentration $(0.4 \mathrm{wt} . \%$ compared to $0.3 \mathrm{wt} . \%$ ) in this alloy with respect to the others resulted in iron neutralization. Hence, formation of the $\beta$-AlFeSi platelets and $\alpha$-AlFeMnSi starshaped was suppressed significantly.

The average noise impedance measured in the low chloride solution increases as the iron-rich phases enlarge. The size of the iron-rich phase particles increases with the iron addition, except for the alloy containing $1.2 \mathrm{wt} . \% \mathrm{Fe}$. Hence, this alloy and the alloy with the lowest iron addition showed a modest noise impedance in the dilute solution, especially after 100,000 seconds of immersion. The addition of copper by $0.5 \mathrm{wt} . \%$ in the LM24-0.8Fe alloy generated the highest average noise impedance in the highly aggressive solution, and this value is much higher than that of the same alloy in the low chloride solution. The volume of corrosion products on the cathodic sites such as iron-rich and copper-rich phases in this alloy led to reduction of the cathodic reaction rate. As a result, the corrosion rate decreased and the measured average noise impedance increased for this alloy. The iron-rich phase particles were dispersed in the LM24-1.2Fe alloy; therefore, the cathodic reaction occurred throughout the surface, and the average noise impedance decreased for this alloy.

The EDX analyses and scanning electron micrographs showed severe dissolution of aluminium matrix rather than silicon in the electrochemical polarisation measurement, because the measured concentration of silicon was much higher 
than that of aluminium. It shows that potentials higher or lower than corrosion potentials caused severe attack and hence, the difference in corrosion behaviour is not shown significantly. As a result, linear sweep test does not provide appropriate comparison criteria for LM24 alloys with various iron contents.

The potential maps for the LM24 alloys showed distribution of phases with various surface potentials throughout the microstructure. The corrosion rate increases with increasing surface potential gradient. Some areas, shown as dark orange, had the lowest surface Volta potentials. The surface areas and shapes of the phase particles are as important as their surface Volta potentials. According to scanning electron microscopy observations, the iron-rich phase particles were large in the LM24-0.8Fe and LM24-2Fe alloys due to high iron contents. The presence of a higher manganese concentration distributed the iron-rich phase particles in the LM24-1.2Fe alloy, and the cathodic sites were smaller than those of the LM24$0.8 \mathrm{Fe}$ alloy irrespective of the higher iron content.

Furthermore, the $\alpha$ and $\beta$ iron-rich phase particles had sharp morphologies, and they showed higher surface Volta potentials in the scanning Kelvin probe micrographs due to their surface roughness, which affects the measured surface Volta potential. In addition, since these phase particles were large in the LM24$0.8 \mathrm{Fe}$ and LM24-2Fe alloys, it was not easy to grind these phases during sample preparation, and they have a higher height with respect to the matrix. Hence, the large iron-rich phase particles showed higher surface Volta potentials in potential maps of these alloys. The alloy with $1.2 \mathrm{wt}$ \% iron showed smaller iron-rich phase particles; therefore, the cathodic areas were smaller than those observed in the alloys containing $0.8 \mathrm{wt} . \% \mathrm{Fe}$ and $2 \mathrm{wt} . \% \mathrm{Fe}$ contents.

\section{Conclusion:}

1) The larger iron content in the LM24 alloy resulted in larger and more complex iron-rich phase particle morphologies and a more corrosion resistant alloy in the presence of $3.5 \mathrm{wt} \% \mathrm{Cu}$. The corrosion products accumulated in the alloys with the larger iron-rich phase particles and resulted in lower rates of cathodic reactions during immersion in $\mathrm{NaCl}$ solutions. 
2) An increased $\mathrm{Mn} / \mathrm{Fe}$ ratio causes the distribution of iron-rich phase particles and cathodic sites across the surface of the alloy. Hence, the compositional potential gradient of the phases throughout the surface decreases.

3) Corrosion depth was narrow in the alloys containing $0.6 \mathrm{wt} . \%$ and $1.2 \mathrm{wt} . \%$ due to smaller iron-rich intermetallic compounds observed in these alloys.

4) The iron-rich and the copper-rich phase particles had potentials in the range of more than $150 \mathrm{mV}$ according to the scanning Kelvin probe force measurements. In addition to the compositional gradient, roughness of the iron/copper-rich intermetallic phase particles resulted in the gradient of surface Volta potential. This gradient was less evident in the alloy containing a higher manganese content due to presence of small and granular iron-rich intermetallic phase particles rather than the $\alpha$ and $\beta$ iron-rich phase particles.

Acknowledgements: The authors acknowledge EPSRC for support of the LATEST2 Programme Grant and the TARF LCV Grant. 


\section{References:}

1. Ambat, R., Davenport, A.J., Scamans, G.,M., Afseth, A., Effect of ironcontaining intermetallic particles on the corrosion behaviour of aluminium. Corrosion science, 2006. 48(11): p. 3455-3471.

2. Belov, N.A., A.A. Aksenov, and D.G. Eskin, Iron in aluminium alloys: impurity and alloying element. 2002: CRC Press.

3. Mondolfo, L.F., Aluminum alloys: structure and properties. Vol. 5. 1976: Butterworths London.

4. Villars, P. and L.D. Calvert, Pearson's handbook of crystallographic data for intermetallic phases. Vol. 2. 1985: American Society for Metals Metals Park, $\mathrm{OH}$.

5. Barlock, J.G. and L.F. Mondolfo, Structure of Some Aluminum-IronMagnesium- Manganese-Silicon Alloys. Zeitschrift fur Metallkunde, 1975. 66(10): p. 605-611.

6. Davignon, G., Verlinden, B., Delaey, L., Serneels, A., An isothermal section at $550^{\circ} \mathrm{C}$ in the Al-Rich corner of the Al-Fe-Mn-Si system. Metallurgical and Materials Transactions A, 1996. 27(11): p. 3357-3361.

7. Phillips, H. and P. Varley, Inst. Metals, 1943, 69, 317.* HWL Phillips. Inst. Metals, 1946. 72: p. 151.

8. Phragmen, G., On the phases occurring in alloys of aluminium with copper, magnesium, manganese, iron, and silicon. Journal of the Institute of Metals, 1950. 77(6): p. 489-551.

9. Shabestari, S., The effect of iron and manganese on the formation of intermetallic compounds in aluminum-silicon alloys. Materials Science and Engineering: A, 2004. 383(2): p. 289-298.

10. Zakharov, A., I. Guldin, and A. Arnold, Phase Diagram of the Al--Si--Fe--Mn System in the 10-14\% Si, 0-3\% Fe, and 0-4\% Mn Concentration Ranges. Russ. Metall., 1989(4): p. 209-213.

11. Zhang, Z., Tezuka, H., Kobayashi, E., Sato, T., Effects of the Mn/Fe Ratio and Cooling Rate on the Modification of Fe Intermetallic Compounds in Cast A356 Based Alloy with Different Fe Contents. Materials Transactions, 2013. 54(08): p. 1484-1490.

12. Taylor, J.A. The effect of iron in Al-Si casting alloys. in 35th Australian Foundry Institute National Conference, Adelaide, Australia. 2004.

13. Aziz, P. and H. Godard, PITTING CORROSION CHARACTERISTICS OF ALUMINUM INFLUENCE OF IRON AND SILICON. Corrosion, 1954. 10(cf. NSA 6-6050).

14. Bond, A., Bolling, G., Domian, H., Biloni, H., Microsegregation and the Tendency for Pitting Corrosion in High - Purity Aluminum. Journal of The Electrochemical Society, 1966. 113(8): p. 773-778.

15. Chen, G., M. Gao, and R. Wei, Microconstituent-induced pitting corrosion in aluminum alloy 2024-T3. Corrosion, 1996. 52(1): p. 8-15.

16. Hubner, W. and G. Wranglen, Scandinavian Corrosion Congress. 1964, Helsinki.

17. Mattsson, E., Gullman, L., Knutsson, L., Sundberg, R., Thundal, B., Mechanism of Exfoliation (Layer Corrosion) of $\mathrm{AI}-5 \% \mathrm{Zn}-1 \% \mathrm{Mg}$. British Corrosion Journal, 1971. 6(2): p. 73-83.

18. Reboul, M. and J. Bouvaist, Exfoliation corrosion mechanisms in the 7020 aluminium alloy. Materials and Corrosion, 1979. 30(10): p. 700-712. 
19. Rynders, R.M., Paik, C.H., Ke, R., Alkire, R.C., Use of in situ atomic force microscopy to image corrosion at inclusions. Journal of The Electrochemical Society, 1994. 141(6): p. 1439-1445.

20. Zahavi, J. and J. Yahalom, Exfoliation corrosion of AlMgSi alloys in water. Journal of The Electrochemical Society, 1982. 129(6): p. 1181-1185.

21. Tegun, O., Japan Institute of Light Metals, Journal, 1986. 18(127).

22. Seri, O. and N. Masuko, Japan Institute of Light Metals, Journal, 1985. 35(98).

23. SERI, O. and K. TAGASHIRA, Active reaction of CrAl 7 intermetallic compound in Al-Cr alloys by cathodic treatment. Japan Institute of Light Metals, Journal, 1988. 38: p. 379-385.

24. Seri, O., The effect of $\mathrm{NaCl}$ concentration on the corrosion behavior of aluminum containing iron. Corrosion science, 1994. 36(10): p. 1789-1803.

25. Arrabal, R., Mingo, B., Pardo, A., Mohedano, M., Matykina, E., Rodriguez, I., Pitting corrosion of rheocast A356 aluminium alloy in $3.5 \mathrm{wt} \% \mathrm{NaCl}$ solution. Corrosion Science, 2013. 73: p. 342-355.

26. Fang, X., Shao, G., Liu, Y.Q., Fan, Z., Effects of intensive forced melt convection on the mechanical properties of Fe containing Al-Si based alloys. Materials Science and Engineering: A, 2007. 445: p. 65-72. 